\title{
Fray Servando Teresa de Mier, Simón Bolívar und die Rhetoriken der Unabhängigkeitsrevolution
}

José Joaquín Fernández de Lizardi hat vielfach darauf hingewiesen, dass sein Periquillo Sarniento nicht nur den Lebenslauf eines einzigen außergewöhnlichen Individuums darstelle, sondern viele derartige Leben verkörpere. Wenn also auf der utopischen Insel im Pazifik kein Platz für Herumtreiber, Betrüger und Taugenichtse war, insofern sie von ihr und ihrer Gemeinschaft verbannt wurden, so war die Zahl der Pícaros - glaubt man dem neuspanischen Autor - im Vizekönigreich doch beträchtlich. Wie repräsentativ aber auch immer der Periquillo Sarniento für die neuspanische Gesellschaft gewesen sein mag: Es handelt sich ,nur‘ um ein Stück Literatur, also nicht um soziologische Statistik, sondern ein gutes Stück neuspanisch-mexikanischen Lebenswissens.

Mit einem weiteren neuspanischen oder, wenn Sie so wollen, mexikanischen Autor desselben Zeitraums verändert sich unsere Perspektivik aber nochmals grundlegend, insofern diese Gestalt zugleich ein anderes Licht auf die transatlantischen Beziehungen wirft. Mit ihm machen wir jenen kleinen Schritt von der Verwendung eingebauter autobiographischer Gattungsformen zur Form der Autobiographie, welche den Anspruch erhebt, in der Nachfolge Jean-Jacques Rousseaus authentisch und persönlich die Erlebnisse eines bestimmten Menschen (literarisch) darzustellen: Ich spreche von den Schriften des mexikanischen Dominikanermönchs Fray José Servando Teresa de Mier Noriega y Guerra, dessen Lebensdaten fast die von Lizardi und seinem Periquillo sind, wurde er doch am 18. Oktober 1765 geboren und verstarb am 3. Dezember 1827.

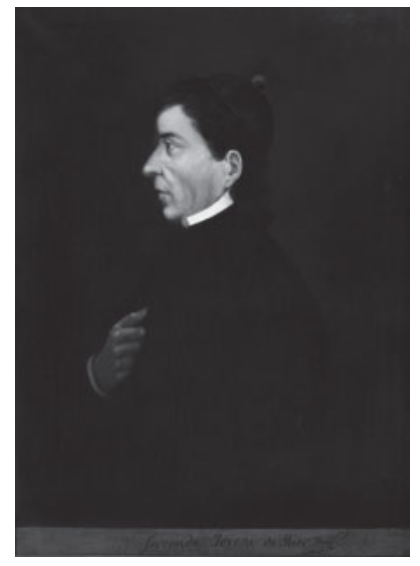

Abb. 31: Servando Teresa de Mier

(Monterrey, Mexiko, 1763 - Mexiko-Stadt, 1827). 
Im Kampf um die Unabhängigkeit der ehemaligen spanischen Kolonien in Amerika und insbesondere um sein Neuspanien hatte der Dominikanermönch eine höchst aktive, wenn auch nicht immer sehr glückliche Rolle eingenommen. In der Bewegung der Independencia fand er nach einer Formulierung Lezama Limas die Fülle seiner Rebellion. In seinem für die ,Wiederentdeckung' Fray Servandos so wichtigen archipelartig aufgebauten Essay La expresión americana hatte der kubanische Romancier, Lyriker und Essayist José Lezama Lima das persönliche, literarische und politische Schicksal des Mexikaners Revue passieren lassen und kam in seinem Kapitel „El romanticismo y el hecho americano“ über die Entstehung der Romantik in einem amerikanischen Kontext zu folgender Einschätzung:

Bei ihm geht die religiöse Verfolgung in die politische Verfolgung über, und als er in London ist und Nachrichten vom Aufstand eines Pfarrers namens Hidalgo erhält, verfasst er sogleich Flugschriften, welche die separatistischen Einstellungen rechtfertigen. Er streift um die Kerker und nähert sich freundschaftlich dem Liberalismus von Jovellanos an, kämpft gegen die französische Invasion oder geht mit den Verschwörern von Mina an Land: Am Ende findet er mit der Proklamation der Unabhängigkeit seines Landes die Fülle seiner Rebellion und jene Form, welche seine Reife brauchte, damit sein Leben schließlich den Sinn seiner historischen Projektion zu erreichen vermochte.

In Fray Servando, in diesem Übergang vom Barock zur Romantik, überraschen wir verborgene und höchst amerikanische Überraschungen. Er glaubt mit der Tradition zu brechen, wo er sie doch erweitert. So trifft er, wenn er sich vom Spanischen zu trennen glaubt, doch wieder darauf, nur erweitert. ${ }^{1}$

José Lezama Lima weist hier zum einen darauf hin, wie die persönlich bedingte Rebellion, die aus bestimmten gesellschaftlichen, religiösen und individuellen Bedingungen erwächst, in politische Revolte und Revolution einfließt, ja wirklich umschlägt. Zum anderen ordnet er den Dominikanermönch einer Zwischenstellung zu, die vom kolonialspanischen Barock zur amerikanischen Romantik hinüberleitet, welche - sehen wir im spanischsprachigen Raum einmal von Kuba und Puerto Rico ab - im Raum der Amerikas eine literarische Bewegung innerhalb politisch unabhängig gewordener Gesellschaften ist. Fray Servando Teresa de Mier wird damit in einer ganz besonderen Weise zu unserem Gewährsmann für die „amerikanische Ausdrucksweise“ an einer Schlüsselstelle des Übergangs zum 19. Jahrhundert, gerade auch hinsichtlich jener von Lezama Lima aufgezeigten Dimension eines vermeintlichen Bruchs mit der hispanischen Tradition, der im Grunde keinen Bruch, sondern ein neues Anknüpfen an verschüttete Traditionen bedeute.

1 Lezama Lima, José: La expresión americana. Madrid: Alianza Editorial 1969, S. 91. 
Für Fray Servando Teresa de Mier bot der Unabhängigkeitskampf der spanischen Kolonien in Amerika die einmalige und unwiederbringliche Chance, in dieser politischen Auseinandersetzung der Passivität, dem bloßen Reagieren auf neue Gefahren entgehen, die Wurzeln seiner ständigen Verfolgungen fassen und für seine Vorstellungen und Überzeugungen aktiv eintreten zu können. Er steht in seinen Anfängen noch im Barockzeitalter, wird zu einem Teil jener neuspanischen Aufklärung, deren Bedeutung erst so spät in Europa erkannt zu werden beginnt, und entwickelt ausgehend von den Errungenschaften der Aufklärung ein deutlich romantisch akzentuiertes Bild von Unabhängigkeit und Freiheit, das sich mit seiner pikaresken Gestalt auf faszinierende Weise verbindet.

Doch dieser nur kurz umrissene und skizzierte Weg war alles andere als ein Spaziergang durch die Geschichte. Der Leidensweg von Fray Servando Teresa de Mier beginnt mit jener denkwürdigen Predigt am 12. Dezember 1794 zu Ehren der Jungfrau von Guadalupe in Mexiko-Stadt. Sie wird zum Ausgangspunkt einer jahrzehntelangen Verfolgung, die mehr als die Hälfte seines über sechzig Jahre langen Lebens andauern wird. Aber wie konnte eine kurze Predigt eine solche Wirkung zeitigen?

Fray Servando griff in seiner Predigt auf eine Tradition zurück, die sich bereits in den ersten Jahren nach der Conquista herausgebildet hatte. Auf eine Vielzahl von Analogien zwischen indigenen und christlichen Riten gestützt war die Ansicht entstanden, dass der Neue Kontinent bereits vor Ankunft der Spanier christianisiert worden beziehungsweise mit der christlichen Lehre in Verbindung gekommen sei. ${ }^{2}$ Fray Servando griff im Angesicht des spanischen wie des neuspanischen Klerus auf dieses Erklärungsmuster zurück. Der junge Dominikaner verteidigte den Glauben, die Erscheinung der Jungfrau von Guadalupe - die längst schon zur Patronin Mexikos und, wenn man so will, zu einer nationalen Symbolfigur geworden war - sowie das von ihr hinterlassene Bildnis stammten nicht aus der Zeit nach der spanischen Eroberung. Vielmehr gingen sie zurück auf eine erste Missionierung Amerikas durch den Heiligen Thomas, den man später unter dem Namen des Quetzalcóatl weiterverehrt hätte. Das war fürwahr unerhört! War sich der junge Prediger Fray Servando Teresa de Mier dieser Tatsache bewusst?

Man darf daran gewiss Zweifel formulieren: Denn diese synkretistische Verbindung zweier religiöser Traditionen zu einer letztlich nationalen Symbolik ${ }^{3}$

2 Vgl. hierzu auch Todorov, Tzvetan: Die Eroberung Amerikas. Das Problem des Anderen. Aus dem Französischen von Wilfried Böhringer. Frankfurt am Main: Suhrkamp 1985, S. 246-250.

3 Vgl. Reyes, Alfonso: Prólogo a Fray Servando. In (ders.): Obras completas. México: Fondo de Cultura Económica 1956, S. 552. Dort auch weiterführende Literatur zur Jungfrau von Guadalupe; zur politischen Dimension des Marienkultes vgl. Aguila, Yves: Sur les prémices d'un sentiment 
bezog ihre politische Explosivität daraus, dass die Verlegung der göttlichen Erscheinung in die vorkolumbische Zeit einer heilsgeschichtlichen Legitimation der spanischen Conquista logischerweise den Boden entzog. Damit aber war das zentrale Ideologem des spanischen Kolonialismus berührt und eine göttliche Rechtfertigung jeglicher spanischen Herrschaft auf dem amerikanischen Kontinent in Frage gestellt.

Der bei der Predigt anwesende höhere, aus Spanien stammende Klerus erkannte diese Gefahr und reagierte umgehend: Erzbischof Núñez de Haro ließ gegen diese, dem kreolischen Selbstverständnis entsprungene Vorstellung und ihren Vertreter predigen und entzog Fray Servando bereits am folgenden Tage die „missio canonica“. Der Spanier griff hart durch und man wollte ein Exempel statuieren. Wenn man sich die besondere Rolle, die der mexikanische Klerus bei der Unabhängigkeitsrevolution in Neuspanien spielte, vor Augen hält, so erscheint die Reaktion des Kirchenoberen aus dessen Perspektive sehr wohl verständlich. Eine erzwungene Widerrufung seiner Position, die der junge Dominikaner mit dem Hinweis auf die Ungemütlichkeit des Gefängnisses begründete, änderte nichts mehr an der Entscheidung: Fray Servando Teresa de Mier wurde $1795 \mathrm{zu}$ zehnjähriger Verbannung nach Spanien in ein Kloster bei Santander verurteilt.

Damit beginnt nun jener zentrale Abschnitt im Leben des Dominikaners, der ihn nach Europa, genauer: nach Spanien, Frankreich, Italien, Portugal und England führte. Fray Servando steht genau im Fadenkreuz jener transatlantischen Beziehungen, welche sich bereits im Vorfeld der Unabhängigkeitsbestrebungen grundsätzlich verändert hatten und die spanische Kolonialherrschaft über Neuspanien in der Tat ins Wanken bringen sollten. Spanien war im Zuge des erwähnten geokulturellen Dominanten-Wechsels schon lange nicht mehr das geistige Mutterland der in Amerika geborenen Kreolen.

Diese sogenannte ,Reise' des Dominikaners, die nichts anderes als eine nie enden wollende Kette von Verfolgungen, Gefängnisaufenthalten und erstaunlicherweise immer wieder gelingenden Ausbruchsversuchen war, steht unter einem ganz anderen Zeichen als Alexander von Humboldts Reise in die Neue Welt, die fast zeitgleich stattfand und mit der wir uns später noch beschäftigen werden. Der Unterschied wird bereits im Titel deutlich: Denn war die Reise in die ÄquinoktialGegenden von Humboldt und Bonpland eigenständig unternommen worden, so lautet das Kernstück der sogenannten Memoiren des Dominikaners Relación de lo que sucedió en Europa al Doctor Don Servando Teresa de Mier después que fué tras-

national en Nouvelle Espagne (1805 - 1810). In: Pérez, Joseph et al. (Hg.): Esprit créole et conscience nationale. Essais sur la formation des consciences nationales en Amérique Latine. Paris: Editions du Centre National de la Recherche Scientifique 1980, S. 69-96. 
ladado allá por resultas de lo actuado contra él en México, desde julio de 1795 hasta octubre de 1805. Die passiven Verbformen drücken deutlicher als alles andere die Unfreiwilligkeit des ganzen Geschehens aus, von dem Fray Servando berichtet. Denn es handelte sich nicht um eine Forschungsreise, sondern zunächst um eine Überstellung in ein spanisches Gefängnis zur Umerziehung eines aufmüpfigen Klerikers, den man im Mutterland wieder zur Räson bringen wollte.

Ist der erste Teil der Relación noch ganz autobiographischen Darstellungsformen verpflichtet und versucht, den Leser zum Zeugen der Unschuld des Autors zu machen - so wie Rousseau in den Confessions einst mit dem Buch in der Hand der Gerechtigkeit teilhaftig werden wollte -, so tendiert der Text in seinem weiteren Verlauf immer stärker zu deskriptiven Formen. Er wird zu einem manchmal phantasievoll ausgeschmückten (da den phantastischen Reisebeschreibungen nachempfundenen) Reisebericht, ja zum Versuch einer Darstellung der bereisten Länder. Fray Servando beschrieb in seinen Memoiren freilich weder Natur noch Landschaft; es standen vielmehr politische und administrative Vorgänge und Gegebenheiten sowie Sitten und Bräuche im Vordergrund. Die Geographie Spaniens, die Fray Servando höchst schmerzhaft, „a golpes y palos“4 auf seinen erzwungenen Reisen erlernte, interessiert ihn freilich kaum. So hält er auch die Sierra de Guadarrama, verantwortlich für die den Kreolen so schreckende Kälte von Madrid, für einen Ausläufer der Pyrenäen. ${ }^{5}$ Verwunderlich ist diese Fehleinschätzung angesichts mangelnder geographischer Kenntnisse hinsichtlich Spaniens um die Jahrhundertwende nicht, sollte doch erst Alexander von Humboldt mit Hilfe einer sehr genauen Messtechnik feststellen, dass das Land in seinen zentralen Teilen aus einer inneren Hochfläche besteht.

In Fray Servandos Relación lässt sich eine grundlegende Tendenz zum Romanhaften, genauer noch zum pikaresken Roman nicht übersehen. Offenkundig war der Dominikaner mit den literarischen Formen der Novela picaresca als Erzählmodell bestens vertraut. Der Autor selbst war sich dieser Tatsache sicherlich bewusst: Wir dürfen in ihm einen eifrigen Leser dieser populären literarischen Gattung vermuten. So taucht beispielsweise die Figur eines „Alcalde“, eines höheren Beamten auf, der in Erwartung eines umfangreichen Schuldgeständnisses von Fray Servando die Geschichte seines Lebens zu hören bekommt. Diese Geschichte wird selbstverständlich während des Verhörs fleißig protokolliert und mitgeschrieben. Ihre Wirkung bei den Behörden ist nicht überraschend:

4 Mier, Fray Servando Teresa de: Memorias. Edición y prólogo de Antonio Castro Leal. México: Editorial Porrúa 1946, Bd. II, S. 244: „mit Schlägen und Knüppeln.“

5 Ebda., Bd. II, S. 188. 


\begin{abstract}
Als ich dazu kam, ihm zu sagen, dass mein Vater Gouverneur und Generalkommandierender im Königreich Neu-León gewesen war, drehte sich der Alkalde überrascht um, da man mich als Kleriker anklagte und es ungewöhnlich war, dass es sich dabei um ein distinguiertes Individuum handelte. Danach machte er mit sehr langen Fragen weiter, und ich antwortete ihm, dass ich ihm mein ganzes Leben erzählen würde; und da ich dies tat, befahl er dem Schreiber, alles zu notieren, was ich selbst ihm diktieren würde. Meine Geschichte erschien ihm wie ein Roman und gewiss ein fingierter, weil nichts mit der Anklage laut königlicher Order übereinstimmte. So ging ich wieder in meinen Kakerlaken-Kerker zurück, um auf Backsteinen zu schlafen, ohne eine andere Kleidung als jene, die ich anhatte, und als Kopfkissen nichts als mein Taschentuch. ${ }^{6}$
\end{abstract}

Fray Servando wird nach dem Verhör in seine Zelle, in seinen Kakerlaken-Keller zurückgebracht. Die erste Darlegung seiner Erlebnisse erscheint einem ersten literarisch eingeführten Zuhörer als reine Fiktion, als etwas, das er als „Roman“ bezeichnet. Doch auch der Ich-Erzähler spricht bewusst von der „narración de mis aventuras " 7 und unterstreicht damit die Nähe zur Form des Abenteuerromans mit seiner Abfolge von Prüfungen und Abenteuern, die der Held zu bestehen hat. Kein Zweifel: Fray Servando war sich der erzählerischen und literarischen Implikationen der ,Abenteuer' in seinen Memoiren wohl bewusst.

So könnte man durchaus sagen, dass sich in den Schriften Fray Servandos Pícaro-Roman sowie Leben, Fiktion und Realität ständig wechselseitig durchdringen: In ihnen tritt uns der Autor als Pícaro entgegen - José Lezama Lima lag in seiner Analyse Fray Servandos durchaus richtig. Denn auch dies ist eine hispanische Tradition, mit welcher der mexikanische Dominikaner keineswegs brach, sondern die er in neuer Form weiterführte und - wenn Sie so wollen - amerikanisierte, ihrer Expresión americana zuführte. Fray Servando sollte in vielerlei Hinsicht in einem Schüler Lezama Limas, Reinaldo Arenas, einen Nachfolger finden. Denn dieser führte in El mundo alucinante nicht nur die Memoiren hinüber in einen wahnwitzigen Roman, sondern erzählte später sein eigenes Leben in pikaresken Strukturen, die in seiner dem Tode abgerungenen Autobiographie mit dem Titel Antes que anochezca, in ständiger Bedrohung durch Verfolger und Gefängnisse erneut - wenn auch in anderer Verkleidung und anderem Kontext - den Autor als gesellschaftlichen Pícaro vorführen. Stets ist auch hier der Autor beim Schreiben, sogar im Schatten der Gefängnisse, doch ein selbstbestimmter Schriftsteller, der sein Werk genau plant.

Tatsächlich entstanden Fray Servandos Lebenserinnerungen, also seine Apología und Relación, im Gefängnis der Inquisition in Mexiko in den Jahren

6 Ebda., Bd. II, S. 205.

7 Ebda., Bd. I, S. 280. 
1818 und 1819, also in etwa zu jener Zeit, als Fernández de Lizardi seinen Periquillo Sarniento vorlegte. Dass der Dominikaner von weit zurückliegenden Ereignissen überwiegend räumlich und chronologisch zutreffend - soweit sich dies nachprüfen lässt - zu berichten vermag, bezeugt ein hervorragendes Gedächtnis: Memorias also auch in diesem Sinne. Die Bedingungen des obsessiven, vielleicht auch lebensrettenden Schreibens werden im Text selbst in ihrer Materialität angedeutet, etwa am Ende eines Kapitels, bei dessen Niederschrift noch Papier übrig geblieben war. So wird eine neue Anekdote als „Apéndice“ wie folgt eingeleitet: „Da noch dieses Fetzchen Papier übrig blieb, will ich eine Anekdote aus Madrid erzählen, als ich dort zum ersten Mal lebte. “8 Diese Materialität des noch zu beschreibenden weißen Papierfetzens gibt Einblicke in das Leben eines (neu-) spanischen Pícaro. Über sie hinaus wird auch die Mündlichkeit des Erzählens, des „contar“ deutlich skizziert. ${ }^{9}$ Die Lebendigkeit dieses Textes entsteht durch die literarisch durchgeführte Mündlichkeit, die wiederum mit der Gattungsgesetzlichkeit des autobiographischen Schreibens, gewiss aber auch jener des Schelmenromans zu tun hat. Im Gegensatz zur Schriftsprache der spanischen Kolonialmacht stellt diese Mündlichkeit vor allem eine subversive Umgestaltung der spanischen Sprache dar, finden sich in ihr doch Mexikanismen, mündliche Ausdrücke oder Elemente, welche auf die entstandenen neuspanischen Volkskulturen verweisen. Die Mündlichkeit des Textes von Fray Servando Teresa de Mier lässt sich im Übrigen auch damit in Verbindung bringen, dass er stets auf der Suche nach einer Zuhörerschaft oder einem Lesepublikum war, „siempre un hombre en busca de auditorio“. ${ }^{10}$ Sie steht aber gleichzeitig in direkter Verbindung mit der Vielzahl assoziativer Anschlüsse, eingeschachtelter Erzählungen und „digresioncitas“, ${ }^{11}$ welche die Relación Fray Servandos gegen Ende in noch zunehmendem Maße prägen: Fray Servando nahm sich alle Freiheiten bei seiner Gestaltung einer pikaresken Figur.

Der Dominikanermönch konnte während des Schreibens kein genau definiertes Publikum vor Augen haben. Dennoch lassen sich bei genauerer Analyse der von ihm verfassten Texte präzisere Aussagen über das intendierte Publikum machen. Denn an einer Vielzahl von Stellen wendet sich der Mexikaner direkt an seine zukünftigen Leserinnen und Leser. So schildert er, wie ihm die Augen über

8 Ebda., Bd. II, S. 192: „Ya que ha sobrado este pedazo de papel, contaré una anécdota acontecida en Madrid cuando mi primera residencia en ella.“

9 Diese Mündlichkeit des Erzählvorganges ist von großer Wichtigkeit. Eine in dieser Hinsicht aufschlussreiche Stelle findet sich auch in Band II, S. 233.

10 Calvillo, Manuel: Nota previa. In: Mier, Fray Servando Teresa de: Cartas de un americano. 1811-1812. Edición Edición facsimilar. México: Partido Revolucionario Institucional 1976, S. liv.

11 Mier, Fray Servando Teresa de: Memorias, Bd. II, S. 69. 
die korrupte Kolonialverwaltung in Spanien erst spät aufgegangen seien, weswegen er es für umso wichtiger halte, diejenigen seiner Landsleute mit Hilfe seiner Schriften - gleichsam in der Art von „consejos“ und „consejas“ - zu öffnen:

Damals war es, als ich die Augen mit Blick auf die Praxis unserer Regierung öffnete und zugleich auf die Hilfsmittel, welche den Amerikanern auf beiden Wegen, dem geheimen und dem über den Consejo de Indias, zur Verfügung stehen, um ihre Einnahmen und Dringlichkeiten zu sichern, und so wird es gut sein, dass ich meinen Landsleuten die Augen öffne, damit sie absolut niemals darauf vertrauen, Gerechtigkeit zu erlangen, da dieses nur dann gilt, wenn große Gunst oder viel Geld herrscht, damit sie versuchen, hier ihre Klagen soweit sie es können durchzusetzen, selbst bei schlechter Zusammenstellung. Denn dort ist die Macht absoluter, und der Hof und die Tribunale sind käuflicher, und größer die Zahl der Bedürftigen, der Übelwollenden und der Intriganten, so dass die Hilfsmittel schwieriger um nicht zu sagen unmöglich sind für einen Armen, also in einem Wort: Dort geht es nicht um das Gewissen, sondern um Geld und Politik, denn beim Spiel der Intelligenz und Verhalten der Höfe geht es just um das Gegenteil der Moral. ${ }^{12}$

Die hier von Fray Servando angesprochenen „paisanos“ sind die Bewohner jenes Gebietes, das der Mexikaner häufig als „Nuestra América“13 bezeichnet hat. Er versucht, seine Landsleute vor jener, Gerechtigkeit ' im spanischen Mutterland zu warnen, indem er die Korruption und Käuflichkeit in den kolonialen Strukturen der iberischen Kolonialmacht demaskiert. Jegliches Vertrauen in eine wie auch immer geartete Gerechtigkeit am spanischen Hofe zu Madrid sei bei seinen „paisanos" daher nachweislich fehl am Platze.

Der Ausdruck „Nuestra América“, der sich in den spanischen Kolonien der Neuen Welt bis ins 17. Jahrhundert schriftlich zurückverfolgen lässt, zeugt von einer beginnenden Identifikation der Kreolen mit ihrem Kontinent und Geburtsort. ${ }^{14}$ Am Ende des 18. Jahrhunderts ist dieser Ausdruck zu einem wichtigen Bestandteil des Vokabulars der (in der Neuen Welt geborenen) Kreolen geworden. Es scheint jedoch, dass die Bezeichnung bis gegen Ende des 19. Jahrhunderts wieder größtenteils in Vergessenheit geraten ist, ehe José Martí, bei dem der Begriff zum ersten Mal in seinem Essay Guatemala auftaucht, ${ }^{15}$ diese Wortfügung im Laufe seiner politischen Entwicklung immer mehr zu einem kombattiven

12 Mier, Fray Servando Teresa: Memorias, Bd. I, S. 243.

13 Vgl. etwa ebda., Bd. II, S. $173 \mathrm{ff}$.

14 Vgl. Almarza, Sara: La frase „Nuestra América“: historia y significación. In: Caravelle 43 (1984), S. 5-22.

15 Vgl. hierzu Ette, Ottmar: Apuntes para una orestiada americana. José Martí y el diálogo intercultural entre Europa y América latina. In: Revista de crítica literaria latinoamericana (Lima, Peru) XI, 24 ( $2^{\circ}$ semestre 1986), S. 143 ff. Die Verwendung des Begriffes „Nuestra América“ lässt sich bei Martí ungeachtet aller inhaltlichen Veränderungen mithin bis ins Jahr 1877 zurückver- 
Begriff der Einheit des Kontinents umgeschmolzen hat. Ich werde gegen Ende unserer Vorlesung darauf zurückkommen.

Im 18. Jahrhundert ist „Nuestra América“, wohl häufig mit regional wechselnder geographischer Referentialität, je nach Herkunftsort der oder des Sprechenden verwendet worden, bevor sich dann im Zeichen der Independencia ein klar kontinentales Verständnis durchsetzte, welches dem Begriff seine politische Schlagkraft vermitteln sollte. Gewiss blieb zunächst das Bewusstsein der Amerikanität auf eine intellektuelle Elite der Kreolen beschränkt. ${ }^{16}$ Doch hat die lateinamerikanistische Forschung in mehreren einschlägigen Studien - wenn auch nicht bei Fray Servando Teresa de Mier - nachgewiesen, wie die Erkenntnis dieser Einheit gerade auch durch das Exil gefördert wurde, etwa bei Juan Pablo Viscardo (1748 bis 1798). Eben diese mit Amerika verbindende identifikatorische Bewegungskraft des Exils kann man jedoch auch bei Fray Servando ansetzen.

Der Gebrauch des Begriffs „Nuestra América“ als sprachliche Waffe im Kampf um eine zunehmende Eigenständigkeit der noch spanischen Kolonien lässt sich bereits in den Memoiren des neuspanischen Dominikaners deutlich erkennen. Sprach etwa ein Alexander von Humboldt aus europäischem Blickwinkel vom Neuen Kontinent, von der Neuen Welt und von Spanisch-Amerikanern, so betonte Mier seine Zugehörigkeit zu „Nuestra América“ und betrachtete sich nicht länger als ,hispanoamericano“, sondern vielmehr als „,americano“. So gab er auch seiner Auseinandersetzung mit dem spanischen Publizisten Blanco White den Titel Carta de un Americano al Español ${ }^{17}$ und betonte die Bezeichnung „Amerikaner“, die bis weit ins 18. Jahrhundert auch im deutschsprachigen Raum zumeist für die Bezeichnung der indigenen Bevölkerung verwendet wurde. Erst später und mit dem Aufstieg der Vereinigten Staaten von Amerika erhielt sie ihre zweifellos usurpatorische, wenn auch nicht unumstrittene Bedeutung.

Es deuten sich bei Fray Servando Teresa de Mier Entwicklungen an, die dann - wie José Lezama Lima in seiner scharfsinnigen Analyse schloss - im Werk und Wirken José Martís kulminieren und ihren semantischen Höhepunkt errei-

folgen und nicht wie laut Sara Almarza (La frase „Nuestra América“: historia y significación, S. 21) nur bis 1883.

16 Vgl. Minguet, Charles: Le sentiment d'américanité dans le mouvement émancipateur des colonies espagnoles d'Amérique. In: Romanistische Zeitschrift für Literaturgeschichte (Heidelberg) 6 (1982), S. 9-23.

17 Vgl. Clavillo, Manuel: Nota previa (1976); zur Geschichte der Begriffe für die ehemaligen spanischen Kolonien in Amerika siehe auch Jurt, Joseph: Entstehung und Entwicklung der LATEINamerika-Idee. In: Lendemains (Tübingen) 27 (1982), S. 17-26; sowie Rojas Mix, Miguel: Bilbao y el hallazgo de América latina: Unión continental, socialista y literaria ... In: Caravelle 46 (1986), S. 35-47. 1986. 
chen sollten. Das Durchlaufen des „histórico calabozo americano“, ${ }^{18}$ also des historischen amerikanischen Kerkers, schafft letztlich jene „expresión americana“, die mit Martí ihre Fülle finden, jedoch gleichzeitig ,jenen Wirbel, der sie zerstören wird“, ${ }^{19}$ erzeugen sollte. Nehmen wir die Ausführungen von Lezama Lima am Ende seines bereits zitierten Essays als einen Ausblick auf das, was uns am Ende des 19. Jahrhunderts in den kulturellen Areas Lateinamerikas erwarten wird:

In einer großen verbalen Weihnacht repräsentiert José Martí die Fülle der möglichen Abwesenheit. In ihm kulminieren der Kerker von Fray Servando, die Frustration von Simón Rodríguez, der Tod von Francisco Miranda, aber auch der Blitz der sieben Intuitionen der chinesischen Kultur, was ihm durch die Metapher des Wissens erlaubt, den Wirbel zu berühren und zu schaffen, der ihn zerstört [...]. ${ }^{20}$

War Alexander von Humboldt beim Verlassen Spaniens im literarischen Text seiner Relation zum Europäer geworden (was sein weltbürgerliches Selbstverständnis nicht behinderte, eher förderte), so wurde Fray Servando Teresa de Mier beim erzwungenen Verlassen Mexikos, also am selben literarischen Punkt seines so ganz anderen Reiseberichts, zum Kreolen. Dort subsumierte er die Gründe für seine Verfolgung in der Heimat durch die von Spaniern beherrschte Geistlichkeit so: „Der Unterschied war klar: Ich bin Kreole und er war ein Europäer.“21 Nur wenige Zeilen später trat Fray Servando auf der Fregatte La Nueva Empresa seine erzwungene Reise nach Spanien an.

Die wiederholte Betonung seiner Identitätszuschreibung als Kreole unterstreicht den Gegensatz zwischen dem spanischen Mutterland und der nun als Heimat empfundenen Kolonie, die auf dem Weg in die Unabhängigkeit ist. Der Gegensatz zwischen dem „español“ oder - wie sich der Mexikaner häufig ausdrückte - „gachupín“ einerseits und dem „,criollo“ andererseits fasst aber bereits bei Fray Servando die Einheit der Amerikaner und damit auch der lateinamerikanischen Welt ins Auge. Zwar ist die Referenz des Begriffs „Nuestra América“ noch schwankend, indem einmal nur „Nueva España“, ein andermal aber alle amerikanischen Kolonien miteinbegriffen sind. Doch lässt sich unter dem prägenden Einfluss des Exils und nicht zuletzt auch durch die Verbindung des Mexikaners mit anderen Exilierten oder mit anderen für die Unabhängigkeit der Kolonien kämpfenden Amerikanern in Madrid, Paris und vor allem London - dem eigent-

18 Lezama Lima, José: La Expresión americana, S. 113.

19 Ebda., S. 116.

20 Ebda.

21 Mier, Fray Servando Teresa de: Memorias, Bd. I, S. 116: „La diferencia era clara: yo soy criollo, y aquel era europeo.“ 
lichen Zentrum der lateinamerikanischen Unabhängigkeitsbewegung - in Europa eine deutliche Entwicklung hin $\mathrm{zu}$ einem wirklich kontinentalen Bewusstsein feststellen. Der Verweis auf José Miranda sowie auf Simón Rodríguez ist hier sehr am Platze. José Joaquín Fernández de Lizardi entwickelte sein kreolisches Bewusstsein und ein wachsendes Gespür für die Unabhängigkeit seines Landes in der Heimat, Fray Servando hingegen unverkennbar im europäischen Exil, wo er sicherlich stärker noch als sein neuspanischer Schriftstellerkollege zu einem ,Proto-Lateinamerikaner‘, einem Bewohner des künftigen Lateinamerika wurde.

So wies Fray Servando Teresa de Mier in seinen politischen Schriften mehrfach und heftig auf die Notwendigkeit einer Einheit innerhalb von „Nuestra América“ hin: „Wir werden frei sein, wenn wir vereint sind.“22 Die Auseinandersetzung mit dem Anderen, dem Fremden - wohl auch unter dem Einfluss der (räumlichen) Distanz - führte bei Mier zu einer neuen Sicht, zu einer neuen Fassung des Eigenen; oder wie der mexikanische Essayist und Theoretiker Alfonso Reyes betonte: „Er betrachtet sein Vaterland aus der Ferne - was eine Art und Weise ist, es besser zu umfassen. "23 Alfonso Reyes sprach aus eigener Erfahrung und wusste, wie furchtbar und fruchtbar zugleich das Exil sein konnte. ${ }^{24}$

Die eigene Herkunft - und für Fray Servando war dies in erster Linie noch Neu-Spanien - ist ihm im Exil dauernd gegenwärtig: „Nie verlor ich Mexiko aus dem Blick, denn ich wollte zurück in mein Vaterland.“ ${ }^{25}$ Dieser Blick auf das Eigene aus der Fremde prägt gewiss auch den Blick auf das Andere, das kolonial Entgegengesetzte, und die literarische Vermittlung des dort Erlebten an die in der Heimat Lebenden. Die Unumgänglichkeit des Vergleichs für diese Vermittlung lässt wiederum Rückschlüsse auf den impliziten Leser der Memoiren zu. Als großen und vielleicht entscheidenden Mangel der Spanier stellt Mier deren Abneigung gegen das Reisen heraus: „Sie reisen nicht, um Vergleiche anzustel-

22 Vgl. Mier, Fray Servando Teresa de: Cartas de un americano, S. 271: „Seremos libres si estamos unidos." Siehe auch die Zusammenstellung von Äußerungen Fray Servandos in O’Gorman, Edmundo: Cronología. In: Mier, Fray Servando Teresa de: Ideario político. Prólogo, notas y cronología por Edmundo O’Gorman. Barcelona: Editorial Lumen 1978, S. xxxviii.

23 Vgl. Reyes, Alfnso: Prólogo a Fray Servando, S. 553: „contempla a su patria desde lejos - que es una manera de abarcarla mejor.“

24 Vgl. zu Alfonso Reyes und seiner Situation im Exil auch Band 3 der „Aula“-Serie in Ette, Ottmar: Von den historischen Avantgarden bis nach der Postmoderne, S. 196-227.

25 Mier, Fray Servando Teresa de: Memorias, Bd. II, S. 59:,Nunca perdía yo de vista a México, deseando volver a la patria“" 
len.“ ${ }^{26}$ Daher seien die Spanier in ihrer dumpfen Abgeschlossenheit auch fest davon überzeugt, trotz ihrer Armut im vortrefflichsten Land der Erde zu wohnen.

An diese Spanier wendet sich Fray Servando nicht; doch lassen gerade die Vergleiche einen Schluss auf die implizite Leserschaft zu. So stellt der Mexikaner die Kleidung der Griechen im Hafen von Marseille - dem alten griechischen Massilia - jener der amerikanischen Indios gegenüber und weist schließlich auch darauf hin, dass Griechinnen und Griechen „den selben Teint wie unsere Indios“ ${ }^{27}$ hätten. Fray Servando beschreibt die Szenerie im Hafen von Marseille, von wo er sich nach Italien begeben will, mit folgenden Worten:

In Marseille sah ich die Frauen, zumindest der gemeinen Schicht, mit Manteldecken wie in Spanien, wo sie alleine Verwendung finden. Auch sah ich eine Kolonie von Katalanen, eine weitere danach in Gibraltar, und wo immer es etwas zu fischen gibt, dort finden sie sich mit diesem Ziele ein. Auch sah ich in einer Stadt, die von den Griechen gegründet, diese selbst zum ersten Male, wie sie Handel treiben. Sie tragen keine Strümpfe, sie tragen eine Jacke oder Baumwolle ganz auf die Art, wie unsere Indios sie tragen, sie haben kurzes Haar und eine Art Mütze oder weiße Kopfbedeckung mit einer Quaste. Die Frauen verwenden eine Tunika; sie sind von rundem Gesicht und haben große Augen. Männer wie Frauen besitzen denselben Teint wie unsere Indios. ${ }^{28}$

Fray Servando entgeht nicht dem Usus, bestimmte Völkerschaften mit HeteroStereotypen zu belegen. Dass zum damaligen Zeitpunkt allen Katalanen etwas gierig Krämerhaftes anhaftet, fehlt selten in spanischen Reiseberichten jener Zeit: Fray Servando bildet da keine Ausnahme. Dass aber ausgerechnet die Griechen, das Kulturvolk des Abendlandes par excellence, von Fray Servando mit den Indianern Amerikas verglichen werden, ist durchaus bedeutungsvoll. Zum einen wird daran ersichtlich, dass sich der anschaulich machende Vergleich an eine amerikanische Leserschaft wendet. Und zum anderen scheint hier im Keim eine Idee zu stecken, die erst von Martí entwickelt und entfaltet, aus-gedacht werden wird: dass die endlich zu erforschende und in die eigene Identität miteinzubeziehende amerikanische Antike - oder wie Martí sich ausdrückte: „nuestra Grecia“29 - in den Reichen der indianischen Hochkulturen zu suchen sei. Für die Aufdeckung dieser dem Kreolen wohl letztlich verborgenen Sichtweise war Fray Servando zu sehr „criollo“, um sich der ganzen Tragweite seiner Sicht bewusst zu werden. Die

26 Ebda., Bd. II, S. 136: „Ellos no viajan para hacer comparación.“

27 Ebda., Bd. II, S. 62: „el mismo colorido de nuestros indios.“

28 Ebda.

29 Martí, José: Obras Completas. La Habana: Editorial Ciencias Sociales 1975, Bd. VI, S. 18. 
nationale Identität verschmolz auch für ihn im Grunde mit der kreolischen. ${ }^{30}$ Die indigene, präkolumbische Vergangenheit wurde noch nicht in das eigene Selbstverständnis miteinbezogen und stand noch isoliert im geschichtlichen Vakuum einer Vor-Zeit, die mit der Gegenwart wenig zu tun hatte. Dies freilich sollte sich im Verlauf des 19. Jahrhunderts erkennbar verändern.

Die Wendung Miers an eine amerikanische Leserschaft wird auch an der Gesamtintention der Darstellung Europas erkennbar, des Reiseberichts also. Fray Servando erwähnt, wenn auch mehr als „anécdota“, ${ }^{31}$ einen lügnerischen Reisebericht über Amerika, der vor allem aus finanziellen Motiven geschrieben worden sei. Beim europäischen Publikum schien folglich eine große Nachfrage nach solchen Reiseberichten $\mathrm{zu}$ herrschen, welche die dominierenden Stereotypen über Amerika bestätigten. Mier schildert nun, wie er gegen diesen ,Reisebericht‘, den ursprünglich französischen Viajero Universal, anzuschreiben und zu polemisieren versuchte, was jedoch vergeblich blieb:

Ich schrieb an Tres Palacios und beklagte mich über die Blasphemien, welche der Viajero gegen den verehrenswerten Bischof Casas veröffentlichte, und dass er bezüglich der Geographie Amerikas absolut ignorant war. Tres Palacios schickte diesen Brief an Estala und sagte ihm, dass wir Mexikaner allesamt so seien und dass er uns dieses Geschäft schwermachen solle. Daraufhin kopierte Estala gegen Amerika und speziell gegen Mexiko alle Absurditäten und Ungereimtheiten von de Pauw und seinen Nachfolgern Raynal, Robertson und Laharpe, so als ob deren Argumente nicht längst von Valverde, Carli, Clavijero, Molina, Iturri, Madison und vielen mehr in Staub aufgelöst worden wären. [...]

So verlaufen alle Dinge in Spanien. Ich begann, gegen den Viajero zu schreiben und um in die Zeitung die Cartas de Tulitas Cacaloxochitl Cihuapiltzin Mexica, eines mexikanischen Fräuleins, gegen den Viajero Universal zu setzen. [...] Doch der Viajero wurde ins Portugiesische übersetzt und diente später als Leitschnur für die englische Geographie von Guthrie, der zudem allen Unsinn von Estala gegen Mexiko abschrieb. So finden die Beleidigungen und die Irrtümer kein Ende. ${ }^{32}$

Es handelt sich damit um eine gesamteuropäische, aus kommerziellen Gründen entstandene und mit verbreiteten europäischen Vorurteilen spielende, verzerrende Darstellung Amerikas, die nicht die Darstellungen etwa der neuspanischen Aufklärung, sondern europäischer Autoren berücksichtigte, die wie Cornelius de Pauw, Guillaume-Thomas Raynal oder William Robertson niemals nach Amerika gereist waren. Dessen ungeachtet aber verbreiteten die Schriften dieser europäi-

30 Vgl. hierzu Aguila, Yves: Sur les prémices d'un sentiment national en Nouvelle Espagne, S. $94 \mathrm{f}$.

31 Mier, Fray Servando Teresa de: Memorias, Bd. II, S. 186.

32 Ebda., Bd. II, S. 187. 
schen Aufklärer eine Vielzahl von - wie wir im Zeitalter Donald Trumps sagen könnten - alternativen Fakten, die jeglicher Grundlage entbehrten und erst mit dem von Alexander von Humboldt mitbewirkten Paradigmenwechsel in den ersten Jahrzehnten des 19. Jahrhunderts ein vorläufiges Ende fanden. ${ }^{33}$ Doch noch ein Hegel kolportierte in seinen geschichtsphilosophischen Visionen - im Übrigen zum Ärgernis Alexander von Humboldts - die völlig irreführenden und falschen ,Erkenntnisse` etwa eines Cornelius de Pauw über die Tropen Amerikas und deren Bevölkerung.

Zweifelsohne lässt sich Fray Servandos Darstellung Europas in Form eines Reiseberichtes aus der Perspektive eines Amerikaners als der gelungene Versuch eines Gegenentwurfs, vielleicht gar - denken wir an den emotionalen Grundton wie auch den oft vehementen Stil der Memoiren, an die ,vehemencia natural de mi estilo“34 und an seine „einfordernde amerikanische Wut“35 - als eine Art literarischer Rache an europäischen Verballhornungen verstehen. Denn es ist auffällig, wie stark Fray Servando gerade die absurden, phantastischen oder skurrilen Seiten der jeweils von ihm besuchten europäischen Länder hervorhebt.

Beispiele für eine derartige Darstellungsweise lassen sich leicht finden und aufzählen. So beschreibt er seinen Landsleuten genüsslich das „ius primae noctis“, das berühmte Beischlaf-Recht der ersten Nacht des Landesherrn anlässlich der Hochzeit seiner Vasallen und Bauern in deutschen Landen. Es handelt sich um ein Thema, das (wenn auch wohl in Unkenntnis der tatsächlichen Rechtsverhältnisse) auch von Wolfgang Amadeus Mozart in einer wunderbaren Oper aufgegriffen worden war. Servando verwendet mehrfach den so bedeutungsträchtigen Begriff der Barbarei in Bezug auf bestimmte Sitten und Bräuche in Spanien sowie Italien ${ }^{36}$ und verweist auf kannibalische Vorkommnisse etwa in Italien. ${ }^{37}$ Vergleiche fallen oft zuungunsten Europas aus; und selbst das Mutterland der hispanischen Zivilisation wird zum Barbarenland erklärt:

Bezüglich der Anlage der Städte gibt es in Europa nichts, was sich mit den Städten in unserem Amerika oder in den Vereinigten Staaten vergleichen ließe. Sie scheinen allesamt von einem Volk gegründet worden zu sein, das den geraden Linien feindlich gegen-

33 Vgl. Ette, Ottmar: Réflexions européennes sur deux phases de mondialisation accélérée chez Cornelius de Pauw, Georg Forster, Guillaume-Thomas Raynal et Alexandre de Humboldt. In: HiN - Alexander von Humboldt im Netz. Internationale Zeitschrift für Humboldt-Studien (Potsdam - Berlin) XI, 21 (2010), S. 1-28 (http://www.hin-online.de).

34 Mier, Fray Servando Teresa de: Memorias, Bd. I, S. 234.

35 Calvillo, Manuel: Nota previa, S. lviii: „,ira americana reivindicadora.“

36 Vgl. etwa Mier, Fray Servando Teresa de: Memorias, Bd. II, S. 68.

37 Ebda. 
überstand. Alles sind krumme Straßen und Gässchen, verzwickt, ohne jede Ordnung und ohne jegliches Erscheinungsbild. [...] In den großen Städten werden die Stadtpläne in Form kleiner Bücher verkauft, um den Ausländer mit der Angabe dessen anzuleiten, was es in ihnen gibt. Allein in Spanien gibt es nichts dergleichen. Es wäre auch vergebens, weil in den Dörfern nur Pfarrer und Küster lesen können. So läuft man wie ein Barbar im Barbarenlande und fürchtet die Banditen, welche die Reisenden ausrauben, und es folgen der Kutsche allein ganze Truppen von Bettlern und Jungs, die schreiend nach Almosen verlangen. ${ }^{38}$

Offenkundig ist es in dieser Passage Fray Servando Teresa de Mier darum zu tun, bei seinen amerikanischen Leserinnen und Lesern den Mythos der europäischen Städte gründlich zu zerstören. Hier spricht nicht nur der Stolz des amerikanischen Kreolen auf die geplanten und geradlinigen Städte von „Nuestra América“, sondern auch der Mexikaner, der allenfalls noch die Entwicklungen in den Vereinigten Staaten gelten lässt, ansonsten aber die Barbarei im vermeintlichen Hort der Zivilisation zu erkennen vermag. Vor allem Spanien ist das Ziel seiner Anklagen, sei man dort zwar davon überzeugt, im vorzüglichsten Land der Erde zu leben, vergleiche sich aber nicht ernsthaft mit anderen Ländern und sehe nicht, wie das Land voller Bettler und Analphabeten ist. Das ehemalige Zentrum der Zivilisation ist aus Sicht eines Amerikaners zu einem Hort der Barbarei und Unwissenheit geworden.

Den Sittenverfall Europas und insbesondere Spaniens lässt Fray Servando gerne daran deutlich werden, dass auch die so hochgeschätzten und christlichkeusch erzogenen Spanierinnen nichts anderes zu tun hätten, als sich öffentlich halbnackt mit entblößten Brüsten zur Schau zu stellen und den Blicken der Männer preiszugeben:

\begin{abstract}
In keinem Teile Europas haben sie so sehr wie die Spanierinnen das Bestreben, ihre Brüste allen Blicken zu zeigen, und in Madrid habe ich sogar Frauen gesehen, die ihre Brüste gänzlich frei promenierten, mit güldenen Ringen durch ihre Brustwärzchen. Dasselbe sieht man an den Zehen ihrer Füße, die gänzlich nackt sind, wie auch die gesamten Arme schon ab der Schulter. Und da sie ihre Beine nicht auch noch entblößen können, tragen sie fleischfarbene Strümpfe. ${ }^{39}$
\end{abstract}

Vergessen wir nicht, dass wir in Fray Servando Teresa de Mier einen Kleriker, einen Dominikanermönch vor uns haben: Dieser zeigt sich deutlich vom Sittenverfall bei den Frauen in Europa schockiert. Nichts vermag aus seiner Sicht die Spanierinnen dafür zu entschuldigen, bei ihrer - sicherlich deutlich überzeichneten - Mode viel nackte Haut zu zeigen. Unverkennbar spricht aus dieser

38 Ebda., Bd. II, S. $56 \mathrm{f}$.

39 Ebda., Bd. II, S. 162. 
Darstellung die Umkehr des Bildes, das im Gefolge der Chroniken bis in die Zeit der Aufklärung in Europa von Amerika und den freizügigen, lüsternen Amerikanerinnen gezeichnet worden war. In Europa kursierten viele Geschichten von den „Tapadas“40 in Lima, jenen verhüllten Frauen, die sexuell höchst eigenständig und von ihren Männern emanzipiert einen Gestus der Unabhängigkeit zelebrierten, der Mitte des 19. Jahrhunderts noch eine französische Frauenrechtlerin wie Flora Tristan faszinierte. ${ }^{41}$

Dabei wies Fray Servando nicht nur auf die allgemeine Ignoranz der europäischen Bevölkerung, sondern immer wieder auf die Unkenntnis der Europäer gegenüber jener der Kolonien, ihrer Sitten und Geschichte hin. Das Zerrbild, das im Spiegel der europäischen Literaturen von den Kolonien in Amerika entstanden war, wird nun auf Europa zurückprojiziert und den Europäern vorgehalten. Allerdings bleibt der primär angezielte Adressat der Schriften Fray Servandos zweifellos das amerikanische Publikum. Diesem gegenüber erfüllt es die Funktion einer Demythifizierung Europas, einer Zerstörung aller Mythen, welche sich die kolonialen Mutterländer und allen voran die Spanier geschaffen hatten. Die nur wenige Jahrzehnte später obligat (und zum literarischen Topos) werdende Bildungsreise der Lateinamerikaner nach Paris haben diese Darstellungen nicht verhindern können.

Fray Servando strebte gewiss keine länderkundliche Darstellung an, denn eine solche „pertenece a la estadística o la geografía, y hay libros donde estudiarla“: ${ }^{42}$ Eine solche gehöre der Statistik oder der Geographie an, und dafür gebe es Bücher genug. Gleichwohl ist der mexikanische Dominikanermönch bestrebt, ein Gesamtbild der bereisten Länder zu entwerfen, mithin seinen Leserinnen und Lesern durchaus Europa nahezubringen. Allerdings ging es ihm dabei nicht mehr um ein Europa, zu dem man hätte aufblicken müssen, sondern um eines, das für die amerikanische Leserschaft gleichsam auf Augenhöhe war. Unverkennbar ist in diesen ausführlichen Passagen der ganze Stolz eines Bewohners von „Nuestra América“ zu spüren, welcher den Ländern der (Noch-)Kolonialherren mit großer Neugier, aber zugleich mit aufgeklärter Skepsis gegenübersteht.

Seins Vorhaben verwirklicht der mexikanische Amerikaner vor allem im zweiten Teil seiner Relación. Mit Ausnahme der ausführlichen Beschreibung

40 Vgl. Ette, Ottmar: Fuß - Taille - Auge. Europäische Körper/Geschichte(n) der schönen Frauen von Lima. In: Erdmann, Eva (Hg.): Der komische Körper. Szenen - Figuren - Formen. Bielefeld: transcript Verlag 2003, S. 153-162.

41 Vgl. das Flora Tristan gewidmete Kapitel in Ette, Ottmar: ReiseSchreiben. Potsdamer Vorlesungen zur Reiseliteratur. Berlin - Boston: Walter de Gruyter 2020, S. 543-555.

42 Mier, Fray Servando Teresa de: Memorias, Bd. II, S. 53. 
religiöser Riten, der Kirchen und Kunstschätze Roms, welche freilich nicht ohne einen Verweis auf die amerikanische Herkunft des Goldes auskommt, ${ }^{43}$ ist Miers Vorgehensweise primär an bestimmten, ihm symbolhaft erscheinenden Details orientiert, die dann als Gerüst für eine Gesamtdarstellung (und meist Verurteilung) des kolonialistischen Europa dienen. Diese Vorgehensweise einer sehr selektiven, wenn auch häufig recht treffenden Wahrnehmung öffnet den Stereotypen allerdings Tür und Tor. Einige Beispiele hierfür mögen genügen!

So beginnt Fray Servando seinen Besuch in Italien mit den Worten „Jetzt befinden wir uns im Lande der Perfidie, der Täuschung, des Giftes wie des Mordes und des Raubes“. ${ }^{44}$ Italien erscheint auf diese Weise nicht als Wiege der Zivilisation oder Schauplatz einer großen Geschichte, sondern als Hort des Betrugs und Diebstahls, wie es viele Heterostereotypen des Landes zum damaligen Zeitpunkt verkündeten. Seine Rückkehr nach Spanien leitet der von der Inquisition verfolgte Dominikanermönch - wenn auch aufgrund seiner Perspektive wie persönlichen Erfahrungen verständlich - mit den Worten ein: „Und da bin ich wieder im Lande des Despotismus.“45 Zwar betont er, dass man zwischen den verschiedenen Regionen Spaniens sehr wohl unterscheiden müsse, doch stimmen nach seiner Ansicht alle Spanier in bestimmten charakteristischen Eigenschaften überein: „Allesamt sind sie mehr oder minder frech und arrogant, und dabei ignorant und abergläubisch. " ${ }^{46}$ So seien die Katalanen gemäß des verbreiteten Stereotyps stets recht arbeitsam, aber nur auf möglichst viel Geld versessen. ${ }^{47}$ Portugiesen und Italiener seien im Gegensatz zu den Nordeuropäern dreckig (,cochinos“), obwohl sie darin noch von den Mauren übertroffen würden ${ }^{48}-$ und mit welcher Lust zitiert Fray Servando mehrfach gleich den bis heute erhaltenen, doppelt perfiden Spruch, dass Spanien nur aufgrund eines geographischen Irrtums zu Europa gezählt werde! ${ }^{49}$ Es kann kein Zweifel daran bestehen: Der mexikanische Dominikaner versucht, in seinen Schriften bei seinem Lesepublikum in der Neuen Welt so weit als irgend möglich den Mythos Europa zu zerstören.

Auffällig ist an all diesen Äußerungen, wie sehr diese scheinbar auf Erfahrungen aufruhenden Bilder den Stereotypen entsprechen, die innerhalb Europas vom

43 Mier, Fray Servando Teresa de: Memorias, Bd. II, S. 101.

44 Ebda., Bd. II, S. 62: „ya estamos en el país de la perfidia y el engaño, del veneno; el del asesinato y el robo."

45 Ebda., Bd. II, S. 135: „Héteme aquí otra vez en el país del despotismo.“

46 Ebdas., Bd. II, S. 139: „todos fieros y soberbios más o menos, [en ser] ignorantes y supersticiosos.“

47 Ebda., Bd. II, S. 144.

48 Ebda., Bd. II, S. 72.

49 Ebda., Bd. II, S. 74 u. 213. 
jeweils anderen Land in Umlauf waren. Fray Servando brauchte sich in diesem Reservoir an Vorurteilen nur umzuschauen und zu bedienen. Besonders schön lässt sich dies an seinem Spanienbild aufzeigen, das bis in viele Einzelheiten hinein dem negativen der französischen Aufklärung wie der französischen „philosophes“ entspricht. Auch wenn der neuspanische Kleriker den französischen Aufklärungsphilosophen distanziert bis feindlich gegenüberstand, bediente er sich doch reichlich an jenem Schatz an Vorurteilen, welche Frankreich zu einer Drehscheibe europäischer Heterostereotype machte.

Diese essentialistischen Verallgemeinerungen wurden nicht zuletzt immer wieder literarisch vermittelt und perpetuiert, wie dies Fray Servando Teresa de Mier selbst bezüglich des Lateinamerikabildes in Europa erkannt hatte. Gerade Reiseberichte spielten eine zentrale Rolle bei der Herausbildung und Verfestigung von Auto- wie Heterostereotypen, sind sie doch die vorzügliche literarische Gattung einer Vermittlung der Alterität des Anderen. Auch bei den „grands philosophes“ ließ sich die Herkunft vieler aus Reiseberichten übernommener Stereotype nachweisen: ${ }^{50}$ Die zeitgenössische Literatur tat ihr Möglichstes, für die internationale Verbreitung dieser Stereotype zu sorgen. Bevor im 19. Jahrhundert die Romantik dieses negative Spanienbild in Frankreich gänzlich umordnete, ohne allerdings seine einzelnen Elemente wirklich auszutauschen, war für die französischen Aufklärer Spanien das Land des Despotismus schlechthin, für Montesquieu gar der Feind der „raison humaine“ überhaupt. Fray Servando holte sich die Argumente, die er brauchte, dort wo er sie fand, und verwandelte seine Schriften gerne in eine „machine de guerre“ gegen den europäischen Kolonialismus.

Es kam aber bei Fray Servando noch eine weitere und wesentliche Komponente hinzu: Das erwachende Selbstbewusstsein und der Stolz des amerikanischen Kreolen gegenüber den Europäern und ihrer Macht. Die Ankunft Fray Servandos in Madrid, der Hauptstadt des großen imperialen Kolonialreiches, gerät so zum Gegenstand einer hemmungslosen „moqueri“, zur Darstellung eines riesigen, nach Mist stinkenden Dorfes inmitten einer noch riesigeren Wüste voller Ruinen. Madrid wird bei ihm zu einer kadaverhaften Stadt, in der nur noch eine „raza degenerada, que hombres y mujeres hijos de Madrid parecen enanos““, 51 also eine degenerierte Rasse von Kleinwüchsigen leben könnte. War die Dekadenz Spaniens und der Spanier auch ein in Europa weitverbreiteter Gemeinplatz, so wird dieser Degenerierung, die bereits im Stadtplan erkennbar sei, das rechtwink-

50 Vgl. Jurt, Joseph: L'image de l'Espagne en France aus Siècle des Lumières. In: Cosmopolitisme, Patriotisme et Xénophobie en Europe au Siècle des Lumières. Colloque International. Paris: Gonthier-Fink 1987, S. 29-41.

51 Mier, Fray Servando Teresa de: Memorias, Bd. II, S. 160. 
lige Straßennetz der amerikanischen Städte als Gegenbild von Intelligenz und Klarheit entgegengestellt. Fray Servando Teresa de Mier versucht, gerade seiner amerikanischen Leserschaft immer wieder klar zu machen, dass Amerika dem dekadenten Europa in vielen Bereichen längst überlegen sei. Welche Gründe hätte es da für die amerikanischen Kreolen geben können, sich den europäischen Kolonialherren auch weiterhin unterzuordnen?

Spanien - dies ist die wohl zentrale Erkenntnis Fray Servandos - wird in Wirklichkeit nicht von seinem König, auch nicht von seinen Ministern, sondern von den Beamten am Hofe regiert, den „covachuelos“. ${ }^{52}$ Von diesen aber ist keinerlei Gerechtigkeit zu erwarten, herrschen in ihren Kreisen doch Verleumdung, Täuschung und Korruption vor. Der ganze Hof ist in den Augen des neuspanischen Denkers nichts anderes als ein einziges Bordell. ${ }^{53}$ Wer als Amerikaner angesichts dieser Zustände noch an Gerechtigkeit oder eine moralische Legitimation des Mutterlandes glaubt, muss dringend eines Besseren belehrt werden. ${ }^{54}$

Die politische, moralische und religiöse Dekadenz Spaniens, des Feindes der menschlichen Vernunft, wird immer wieder herausgestrichen. Fray Servando Teresa de Mier erweist sich in all diesen Argumentationen nicht nur als Anhänger der neuspanischen Aufklärung, sondern auch als authentischer Vertreter dieser „filósofos“. Dabei verwendet der von der neuspanischen Kirche verstoßene Kleriker durchaus argumentative Schemata, wie sie für die Aufklärung charakteristisch sind. In seiner Apología etwa benutzt Fray Servando ein Grundschema seiner Selbstverteidigung, das sich bereits in den Kapitelüberschriften dieses Werkes abzeichnet, welche kurz zitiert seien: „Die Leidenschaften verschwören sich, um gegen die Unschuld vorzugehen“; „Die Leidenschaften verleumden die Unschuld“; „Die Leidenschaften beleidigen die Unschuld“; „Die Leidenschaften kriminalisieren die Unschuld“ “. 55

Dieses Grundschema ist uns aus der französischen Aufklärung wohlvertraut, bedienten sich doch die „philosophes“ von Voltaire oder Jean-Jacques Rousseau bis hinunter zum unwichtigsten Provinzphilosophen des legitimierenden Bildes der „vertu persécutée“, um ihren selbstlosen Einsatz für ihre Ideen dem Publikum glaubhaft zu machen. ${ }^{56}$ Gerade die Argumentationen des Genfer Philosophen

52 Ebda., Bd. I, S. 234, 241 u. $244 \mathrm{ff}$.

53 Ebda., Bd. II, S. 166.

54 Ebda., Bd. I, S. 243.

55 „Las pasiones se conjuran para procesar a la inocencia“; „Las pasiones [...] calumnian a la inocencia“; „Las pasiones infaman la inocencia“; „Las pasiones acriminan la inocencia“.

56 Vgl. hierzu etwa Gumbrecht, Hans Ulrich / Reichardt, Rolf: Philosophe, Philosophie. In: Handbuch politisch-soziale Grundbegriffe in Frankreich: 1680-1820. Herausgegeben von Rolf Reichardt und E. Schmitt. Fasc. 3. München: Oldenbourg 1985, S. 47. 
bringen an dieser Stelle eine Emotionalisierung des Diskurses zum Tragen, der just in der Romantik auf starke Zuneigung stieß und nicht zuletzt auch auf Fray Servando stark einwirkte. Ungezählte Male in seinen Memoiren beschwor Fray Servando seine geradezu kindliche Einfalt und Unschuld, ${ }^{57}$ seine „,santa sencillez“, ${ }^{8}$ seinen „candor natural“, ${ }^{59}$ „el candor que se notó casi siempre en todos los grandes ingenios ${ }^{* 60}$ und bemühte gar das Rousseau entliehene Bild der Ameisen, die er auf seinen Wegen sorgfältig umgehe, um sie nicht zu verletzen. ${ }^{61}$

Fray Servando ergänzte die von den Aufklärern benutzte Rechtfertigungsstrategie dabei durch die Komponente seiner Amerikanität. Er vertrat gegenüber den Leidenschaften der moralischen Dekadenz in Spanien das Recht der „virtud americana perseguida“, der verfolgten amerikanischen Tugend. Allein auf Grund seiner bewussten Amerikanität werde er verfolgt:

Wenn sich ein böswilliges Spanierlein mit mir hätte aussprechen wollen, hätte ich ihm meine kurzen Zeilen gezeigt, ihn über alles unterrichtet und seiner Provinz die Ausgaben für meine Spesen erspart. Aber was gibt man einem Spanierlein aus der Provinz, aus der er stammt? Das Geschäft besteht ja gerade darin, den Kreolen zu verfolgen [...]. ${ }^{62}$

Fray Servando wäre nun nicht Fray Servando gewesen, hätte er aus dieser Position nicht einen gewiss verschwindend geringen Nutzen gezogen. So ging ihm in Frankreich auf, dass ihm „die Herkunft aus einem so weit entfernten Land wie Mexiko eine Art von mythologischem Status gab, was die Neugier anstachelte und Aufmerksamkeit hervorrief" ${ }^{63}$ Und letztlich half ihm auch sein mexikanischer Akzent - ein distinktives sprachliches Merkmal, das für die Ausbildung einer mexikanischen Identität nicht unwichtig war ${ }^{64}$ - sehr dabei, von den Spaniern an der Pyrenäengrenze als (wie Servando stolz notierte) ,Ausländer‘, als „extranjero“ nicht an der Ausreise nach Frankreich gehindert zu werden. ${ }^{65}$ So konnte er die Grenze nach Frankreich auf jene Art und Weise passieren, in der einst JeanJacques Rousseau dasselbe Frankreich verlassen hatte, um sich der Verfolgung durch seine Flucht in die Schweiz zu entziehen: Er ließ sich den genauen Verlauf

57 Mier, Fray Servando Teresa de: Memorias, Bd. II, S. 227.

58 Ebda., Bd. II, S. 232.

59 Ebda., Bd. II, S. 241.

60 Ebda., Bd. II, S. 239.

61 Ebda., Bd. II, S. 10.

62 Ebda., Bd. II, S. 232.

63 Ebda., Bd. II, S. 61: „el ser de un país tan distante como México me daba una especie de ser mitológico, que excitaba la curiosidad y llamaba la atención.“

$64 \mathrm{Vgl}$. Aguila, Yves: Sur les prémices d'un sentiment national en Nouvelle Espagne, S. $88 \mathrm{f}$.

65 Mier, Fray Seervando Teresa de: Memorias, Bd. II, S. 171. 
der Grenzlinie zeigen, überschritt sie und küsste dann euphorisch den Boden des freien Landes. ${ }^{66}$ Rousseau ist in den Schriften des Mexikaners weitaus präsenter, als dies auf den ersten Blick erscheinen möchte - und als es Fray Servando vielleicht selbst auch wahrhaben wollte.

Letztlich aber wird diese erträumte und ersehnte Freiheit, so Miers Hoffnung, dereinst ihren Sitz in Amerika haben und von dort aus nach Europa zurückstrahlen. Die geistige Auseinandersetzung mit und Anteilnahme an den Ideen der Independencia ließ ihn den Satz Javier Minas niederschreiben, mit dem zusammen er aus England aufbrach, um Mexiko zu befreien: „In Amerika muss Europa befreit werden." ${ }^{67}$ Diese Aussage zeigt an, über welches Selbstbewusstsein als Amerikaner der neuspanische Dominikaner zu Beginn des 19. Jahrhunderts verfügte. Fray Servandos Satz gibt einer Hoffnung und vielleicht mehr noch einer Erwartung Ausdruck, die sich erst ein gutes Jahrhundert später verwirklichen sollte: dass nämlich der Meridian der Weltgeschichte über den Atlantik nach Amerika wandern werde.

Fray Servando begegnete der von ihm konstatierten europäischen Dekadenz ohne Zweifel mit amerikanischem Sendungsbewusstsein. Doch die Verbindung zwischen Europa und Amerika bleibt für den mexikanischen Kreolen konfliktiv und hochemotional. Mir scheint es wichtig, diese Emotionalität festzuhalten, öffnet sie für uns doch einen wichtigen Einblick in eine Befindlichkeit, welche sich angesichts transatlantischer, europäisch-amerikanischer Beziehungen bei vielen Vertretern der amerikanischen Intelligenzija einstellt. Es ist von grundlegender Bedeutung zu verstehen, dass sich diese Beziehungen noch immer an der Schmach kolonialer Abhängigkeit ausrichten - auch bei einem Kreolen, der ja von Spaniern in direkter Linie abstammt und sich von den vorherrschenden „gachupines“ nur dadurch unterscheidet, dass er in der neuen Welt, in „Nuestra América“ geboren wurde. Eine antikolonialistische Emotionalität endet eben nicht mit dem Ende des Kolonialismus, sondern zieht sich noch lange Zeit durch die postkolonialen Beziehungen zwischen den Bewohnerinnen und Bewohnern der ehemaligen Kolonie und des früheren Mutterlandes. Dies ist eine Erfahrung, die Sie ohne Schwierigkeiten auch heute noch machen können.

Selbst historisch mehrere Jahrhunderte zurückliegende Ereignisse bewahren dabei im postkolonialen Imaginären ihren emotionalen Status und führen noch immer zu starken Verwerfungen. Denn als Fray Servando zufällig am Hafen von Palos vorbeikommt, von dem aus Kolumbus die Neue Welt entdeckte, beginnt ihm das Herz zu schlagen: Die sogenannte ,Entdeckung‘ und vor allem die sich

66 Ebda., Bd. II, S. 17.

67 Ebda., Bd. II, S. 253: „En América [...] se ha de libertar a Europa.“ 
anschließende Conquista sind für sein Selbstverständnis als Amerikaner eine grundlegende, traumatische Erfahrung, von welcher er sich nicht leicht zu befreien vermag. Diese Emotionalität beruht auf den ständigen Verletzungen und insgesamt auf der Perspektive des amerikanischen Kreolen, welche die unaufhörlichen Auseinandersetzungen und der ständige Kampf mit der spanischen Kolonialmacht geprägt hatten.

All dies zeigt sich in dem Bild, das Fray Servando von Europa und speziell von Spanien zeichnete. Gerade dieses Spanienbild diente ihm immer wieder als negative Gegendarstellung in seiner Zukunftsvision Mexikos und der aus der Kolonialzeit emergierenden spanischen Kolonien. Fray Servando ging es weit weniger um die globale Entwicklung der Menschheit und eine breitflächige Diskussion ihrer dringlichsten Herausforderungen, sondern um die Lösung der konkreten Probleme Neu-Spaniens innerhalb dessen, was wir als den postkolonialen Prozess bezeichnen dürfen. Ihn interessierten weniger die großen Denksysteme als einzelne Überlegungen französischer Aufklärer, die mit Nutzen auf den lateinamerikanischen Kontext übertragbar sein könnten. Er war darin ein typischer Vertreter der amerikanischen Aufklärung, die eklektisch verschiedenste Traditionen aus der Perspektive spezifischer kreolischer Interessen miteinander verknüpfte. ${ }^{68}$ In diesem eklektischen Zug manifestiert sich zugleich auch eine Vergleichzeitigung von Entwicklungen und Perioden, die in Europa fein säuberlich voneinander getrennt waren. Dies sollte für einen langen Zeitraum zur Grundlage literarischer und kultureller Aneignungsprozesse in (einem in Entstehung befindlichen) Lateinamerika werden.

Vergessen wir dabei nicht, dass Fray Servando zeitlebens ein Gehetzter war: zunächst über lange Jahre von der neuspanischen beziehungsweise spanischen Inquisition als gefährlich denunziert und verfolgt, gegen Ende seines Lebens dann in die politischen Gegensätze der mexikanischen Independencia verstrickt. Erinnern wir nochmals an den bereits zitierten Essay Lezama Limas, um dieses transareale Spannungsfeld genauer zu verstehen:

Fray Servando war der erste Entflohene, ausgestattet mit der notwendigen Kraft, um zu einem Ende zu gelangen, welches alles klärt, von der barocken Herrlichkeit an, vom Herren, der den wollüstigen Dialog mit der Landschaft durchquert. Er war der Verfolgte, welcher aus seiner Verfolgung eine Art der Integration macht. ${ }^{69}$

68 Vgl. hierzu Chiaramonte, José Carlos: Iberoamérica en la segunda mitad del siglo XVIII: la crítica ilustrada de la realidad. In: Pensamiento de la Ilustración. Economía y sociedad iberoamericanas en el siglo XVIII. Caracas: Biblioteca Ayacucho 1979, S. ix-xxxix.

69 Lezama Lima. José: La expresión americana, S. 97. 
So ging Fray Servando ein in die Geschichte der politischen Unabhängigkeit Amerikas als der Verfolgte, dem es immer wieder gelingt, aus allen Gefängnissen, in die man ihn einsperrt, auszubrechen und ständig neue Schriften, neue Pläne, neue Verschwörungen zu entwerfen, wie denn die verhasste Herrschaft der Spanier über ihre amerikanischen Kolonien am besten zu brechen wäre. Und zugleich ging er in die postkoloniale Geschichte der Literaturen Neuspaniens und Lateinamerikas ein als derjenige, der seine Memoiren nach Art einer Novela picaresca anordnete und ganz in dem Sinne, wie José Lezama Lima ihn portraitierte, mit Spanien zu brechen glaubte, um sich dabei umso mehr mit ihm zu verbinden. Wie bei José Joaquín Fernández de Lizardi ist in ihm der spanische Schelmenroman allgegenwärtig und verknüpft sich in emanzipatorischer Geste mit der Amerikanität dieses Literaten, Philosophen und Schriftstellers im Übergang von der neuspanischen Aufklärung zu den Literaturen des 19. Jahrhunderts.

Fray Servando Teresa de Mier hatte in Übersee - insbesondere in Paris und London - Kontakte zu einer Vielzahl von Hispanoamerikanern aber auch Spaniern geknüpft, die aktiv am Prozess der Independencia beteiligt waren und als Vordenker, Kämpfer oder Gestalter diesen Unabhängigkeits-Prozess der spanischen Kolonien in Amerika grundlegend prägten. So hatte Fray Servando nicht nur den Spanier Blanco White kennengelernt, mit dem er manchen Strauß ausfocht, sondern auch Figuren vom Kaliber eines Andrés Bello, mit dem wir uns im Rahmen dieser Vorlesung noch ausführlich beschäftigen werden, oder einen so wichtigen Intellektuellen wie Simón Rodríguez, den Lehrmeister Bolívars, mit dem Fray Servando eine herzliche Freundschaft verband. Man darf ihn daher trotz mancher Eigenwilligkeiten und immer wieder überraschender Wendungen sehr wohl jener Gruppe von Literaten zurechnen, welche die Ideen insbesondere der novohispanischen Aufklärung in die Tat umzusetzen versuchten und damit den Weg für die in Entstehung begriffenen Literaturen bahnten.

Wir kommen damit zu dem vielleicht wichtigsten und sicherlich bekanntesten Vertreter des hispanoamerikanischen Unabhängigkeitskampfes, den Sie wohl eher in einer Vorlesung über Geschichte und Politik Lateinamerikas, vielleicht weniger aber in einer Vorlesung über die romanischen Literaturen im 19. Jahrhundert erwartet hätten. Und doch ist Simón Bolívar nicht nur für die Bereiche Geschichte und Politik des entstehenden Lateinamerika eine wichtige Figur. Zudem ist er nicht nur ,passiver` Gegenstand einer Vielzahl literarischer Darstellungen geworden, von denen eine der gelungensten sicherlich der Roman El general en su laberinto von Gabriel García Márquez ist. Vielmehr ist er ohne jeden Zweifel eine höchst aktive und kreative Gestalt in den Bereichen spanischsprachiger Ideengeschichte und Literatur, vor allem auch, was die literarischen Formen Essay und Brief betrifft. 
Er ist darüber hinaus auch einer jener Männer, die sich zu Beginn des 19. Jahrhunderts mit der größten Luzidität die komplexe Frage nicht nur der politischen Zukunft, sondern auch einer kulturellen Identitätskonstruktion der ehemaligen spanischen Kolonien stellten. Dies ist durchaus außergewöhnlich, ebenso wie die Tatsache, dass in der Geschichte der Menschheit sich niemals ein geographisch größerer Raum in kürzerer Zeit von althergebrachten Gesellschaftsstrukturen hier also dem kolonialen System des spanischen Mutterlandes - hat befreien können. Dies gilt es stets zu bedenken, auch wenn man der Independencia beispielsweise hinsichtlich ihrer politischen und wirtschaftlichen, aber auch gesellschaftlichen und kulturellen Konsequenzen kritisch oder skeptisch gegenüberstehen mag und darauf verweist, dass die Trägerschicht der Unabhängigkeitsrevolution die kreolische Führungsschicht war. Ihr vorrangiges politisches Ziel war es, die lästige Abhängigkeit von Spanien abzuschütteln und wirtschaftlich frei und unabhängig agieren zu können, ansonsten aber ihre Interessen (und Formen der Ausplünderung) zu wahren.

Simón Bolívar wurde als vierter Sohn einer wohlhabenden Familie der Oligarchie am 24. Juli 1783 in Caracas geboren und starb am 17. Dezember 1830 in Santa Marta im heutigen Kolumbien. Er gehört damit grob gesprochen jener Generation an, der wir schon die beiden Mexikaner José Joaquín Fernández de Lizardi und Fray Servando Teresa de Mier zurechnen konnten. Simón José Antonio de la Santísima Trinidad Bolivar y Ponte freilich stammt aus einer überaus angesehenen Oligarchen-Familie, die über weite Besitzungen, Plantagen und Sklaven verfügte. So verwundert es nicht, dass der junge Bolívar eine ausgezeichnete Ausbildung genoss und die besten Schulen besuchte. $\mathrm{Zu}$ seinen Lehrmeistern zählte er selbst seinen bereits erwähnten Landsmann Andrés Bello, vor allem aber den unverkennbar von den Vorstellungen Rousseaus inspirierten Simón Rodríguez.

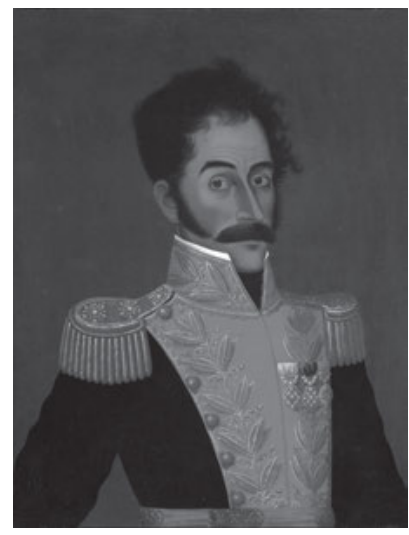

Abb. 32: Simón Bolívar (Caracas, Neugranada, 1783 Santa Marta, Großkolumbien, 1830). 
Übrigens besaß Simón Rodríguez - eine interessante Anekdote am Rande - ein Exemplar von Rousseaus Contrat social, das Napoleon gehört hatte: Der englische General Wilson hatte es ihm abgenommen und Rodríguez geschenkt. ${ }^{70}$ In der Forschung wird gewöhnlich und wohl mit Recht darauf verwiesen, dass Rodríguez dem jungen Bolívar den Kult der Freiheit ebenso eingeflößt habe wie eine gewisse Dosis Megalomanie und Schönheitssuche. ${ }^{71} 1799$ quittierte letzterer nach dem Tod der Eltern seinen Dienst im Heer und ging nach Spanien, wo er in Madrid mit führenden Intellektuellen und Schriftsellern seiner Zeit in Berührung kam. Er war empfänglich für die Impulse des damaligen Zeitgeistes. Mit siebzehn Jahren stattete er dem Frankreich Napoleons einen Besuch ab, wo ihm der Glanz der französischen Hauptstadt imponierte. Nach seiner Heirat in Madrid im Jahr 1802 ging er zurück nach Caracas, wo noch nichts auf die künftige Karriere als Befreier Südamerikas hinwies und er sich um das Wohlergehen seiner mit Hilfe zahlreicher Sklaven betriebenen Kakaoplantagen kümmerte. Doch bald schon verstarb seine Frau; und Simón Bolivar sollte nie mehr heiraten.

Dieses dramatische Ereignis schätzte Bolivar selbst als dermaßen zentral ein, dass er von sich behauptete, niemals zum General Bolívar und zum Kämpfer für die Unabhängigkeit der Kolonien geworden zu sein, wenn seine junge Gemahlin nicht gestorben wäre. Bisweilen hängt die sogenannte ,Große Geschichte‘ von höchst persönlichen Ereignissen oder auch Schicksalsschlägen und damit von der ,Kleinen Geschichte“ entscheidend ab. Doch sollten wir vorsichtig sein, all dies für bare Münze zu nehmen, denn hier nähern wir uns bereits dem an, was jeden beeindruckt, der sich mit dem „Libertador“ auseinandersetzt: die zähe und dichte, stets aber faszinierende und ständig weitergesponnene Existenz des Mythos Bolívar! Noch im heutigen Venezuela, der „República Bolivariana“, wurde unter der Regierung Chávez eifrig am Bolivar-Mythos weitergestrickt. ${ }^{72}$

Doch so öffnet sich die Geschichte des Libertador, den nun keinerlei familiäre Bande mehr zurückhalten: Simón Bolívar kehrt wieder in das Paris Napoleons zurück, wo er mit einer Vielzahl französischer Generäle und Diplomaten in Kontakt kommt und wo er - nebenbei bemerkt - in den Pariser Salons auch auf Alexander von Humboldt trifft, der den jungen Heißsporn nicht recht ernst nimmt

70 Vgl. Van Oss, Adrian: La América decimonónica. In: Iñigo Madrigal, Luis (Hg.): Historia de la Literatura Latinoamericana. Bd. II: Del neoclasicismo al modernismo. Madrid: Ediciones Cátedra 1987, S. 13.

71 Vgl. unter anderem den ersten Beitrag in González, V. et al. (Hg.): Simón Bolivar. Madrid: Grupo 16 1985, S. 4; kritisch zum Bolívar-Mythos vgl. Zeuske, Michael: Simón Bolivar, Befreier Südamerikas. Geschichte und Mythos. Berlin: Rotbuch Verlag 2011.

72 Vgl. Zeuske, Michael: Von Bolívar zu Chávez. Die Geschichte Venezuelas. Zürich: Rotbuch Verlag 2006. 
und für einen puren Salonlöwen hält, der nichts weiter als ein modebewusster Dummkopf sei. Humboldt wird erst dann die ganze Größe dieses Oligarchen und Großgrundbesitzers begreifen, als jene militärischen und politischen Ereignisse einsetzen, die der preußische Natur- und Kulturforscher während seiner Reise durch die amerikanischen Tropen zwischen 1799 und 1804 bereits zu erahnen vermochte. Denn dort traf er sich allerorts mit den Vertretern jener gesellschaftlichen Elite, welche nur wenige Jahre später zur Trägerschicht der kommenden Unabhängigkeitsrevolution werden sollte.

Bolívar wird in der französischen Hauptstadt mit dem politischen Diskurs des französischen Kaisertums, des Empire vertraut: Er erwirbt sich die Vorstellungen von Unabhängigkeit, Volkssouveränität, Fortschritt und Zivilisation, die sein Denken freilich schon seit seinen frühen Jahren bestimmt hatten, und wird vor allem mit einer Herrschaftsform konfrontiert, die aus einer Revolution hervorgegangen war und die man einen aufgeklärten Despotismus nennen kann. Er wird wie viele andere Denker und Intellektuelle des 19. Jahrhunderts Mitglied der amerikanischen Freimaurer in Paris, wo er immerhin den Grad eines „Maestro“ erreicht. $^{73}$

In Paris trifft Bolivar auf seinen geliebten Lehrmeister Simón Rodríguez; und beide unternehmen jene berühmte Reise nach Italien, auf der Bolívar - und auch dies gehört zu seinem Mythos - unter dem Eindruck der Ruhmestaten Napoleons den berühmten Schwur auf den Ruinen des ehemaligen Mittelpunkts des Römischen Reiches ablegt, sein Heimatland von der spanischen Tyrannei zu befreien. Bolívar wird diesen auf dem Forum Romanum geleisteten Schwur mit aller Macht einlösen: Sein ganzes weiteres Leben und Kämpfen kreist um die militärische und politische Durchsetzung der Unabhängigkeit sowie stabiler postkolonialer Verhältnisse in den neu entstandenen staatlichen Strukturen.

Bei seiner Rückkehr nach Caracas im Jahr 1807 war die Lage für die Aufständischen freilich nach Mirandas Scheitern noch nicht günstig, und so widmete Bolívar sich vorerst der Verwaltung seiner großen Hazienda, der Literatur, aber auch der Konspiration, die von großem Gewicht innerhalb der bald einsetzenden Ereignisse sein sollte. ${ }^{74}$ Bolivar selbst äußerte sich 1825 in einem Brief an Francisco de Paula Santander zu seiner eigenen Bildung:

Ich habe nicht aufgehört, so erzogen zu werden, wie ein Kind aus gutem Hause in Amerika unter der spanischen Macht überhaupt ausgebildet werden kann [...]. Es ist nicht zutreffend, dass meine Erziehung ungeordnet war, insofern meine Mutter wie meine Tutoren taten, was

73 González, V. et al. (Hg.): Simón Bolívar, S. 4 f.

74 Ebda. sowie Zeuske, Michael: Simón Bolivar (2011). 
in ihrer Macht stand, damit ich lernte; sie suchten mir in meinem Land Lehrer von allerhöchster Güte.

Robinson (Simón Rodríguez) war mein Lehrer, der mich in die Literatur einführte; in Belletristik und Geographie war es unser berühmter Bello; allein für mich baute man mit Pater Andújar, den Baron von Humboldt sehr schätzte, eine Akademie der Mathematik auf. Danach schickten sie mich nach Europa, um meine Mathematik in der Akademie von San Fernando fortzuführen; und ich lernte mit ausgesuchten Lehrern aus Madrid Fremdsprachen; all dies unter der Leitung des weisen Marquis von Uztaris, in dessen Haus ich lebte. Als ich noch ein kleiner Junge war, vielleicht noch unfähig zu lernen, gab man mir Stunden im Fechten, im Tanzen und im Reiten. Gewiss lernte ich weder die Philosophie des Aristoteles noch die Strafgesetze für Verbrechen und Täuschung; aber es kann sein, dass Monsieur de Mollien nicht soviel wie ich Locke, Condillac, Buffon, D’Alembert, Helvétius, Montesquieu, Mably, Filangieri, Lalande, Rousseau, Voltaire, Rollin, Berthot und alle Klassiker der Antike, darunter Philosophen, Geschichtsschreiber, Redner und Dichter, studierte; einschließlich aller modernen Klassiker aus Spanien, Frankreich, Italien und einen Großteil der Engländer [...]. ${ }^{75}$

Simón Bolívar entwirft uns in dieser Passage die Koordinaten einer Erziehung, die fürwahr dem Spross einer Familie der mächtigen Oligarchie in den spanischen Kolonien Amerikas würdig war. Auch wenn wir dieses Zitat mit einer gewissen Vorsicht zur Kenntnis nehmen sollten, weil Bolívar nicht gerade unter geringem Selbstbewusstsein litt und seinen Werdegang in möglichst leuchtenden Farben darstellen wollte. Doch dürfen wir konstatieren, dass es sich um eine standesgemäße Ausbildung handelte mit den obligaten Aufenthalten in Europa, insbesondere in der Hauptstadt des Mutterlandes Madrid und der geistigen Hauptstadt Paris.

Doch die große Chance und Gelegenheit Bolívars zur Befreiung seines Amerika, von „Nuestra América“, und damit auch des gesamten Kolonialsystems Spaniens sollte sich schon bald bieten, und zwar in Gestalt der napoleonischen Invasion des verhassten spanischen Mutterlandes. Denn diese Schwächung, ja zeitweilige Paralyse Spaniens gab den nach Unabhängigkeit strebenden Kräften in Amerika Hoffnung und genügend Spielraum, um rasch zu agieren und die Weichen in Richtung politischer Unabhängigkeit zu stellen. Der „Capitán General“ Emparán, der noch mit Humboldt verkehrte, wurde abgesetzt, das "Cabildo“ wurde einberufen, und am 19. April 1810 wurde eine Junta eingesetzt, in der sich Kreolen verschiedenster und oftmals gegenläufigster Tendenzen vereinigten.

Simón Bolívar hatte in dieser Bewegung zunächst eine gewisse Außenseiterposition als Radikaler inne; doch sandte man ihn nach London - eine Reise, die er im Übrigen zusammen mit Andrés Bello unternahm -, um die Hilfe der britischen

75 Bolívar, Simón: Escritos políticos. Madrid: Alianza Editorial 1969, S. 19. 
Regierung zu erbitten. Diese konnte eine Unabhängigkeit von Spanien angesichts der politischen Konstellationen in Europa freilich nicht offen unterstützen. Wieder zurück in Caracas, setzte sich Bolívar vehement für die völlige Loslösung von Spanien ein, eine Option, gegen welche es durchaus erheblichen Widerstand gab. Doch die Gruppe um ihn setzte sich durch: Am 5. Juli 1811 wurde feierlich die Unabhängigkeit erklärt, wobei diese sogenannte Erste Republik allerdings nur ein Jahr lang bestand. Es handelte sich dabei um den ersten klaren Bruch mit Spanien auf dem gesamten amerikanischen Kontinent. Im nachfolgenden Krieg unterlagen allerdings die Truppen der „Independentistas“ im Jahr 1812: Miranda - der Jahre zuvor bereits einen freilich vergeblichen Versuch unternommen hatte, in Venezuela das spanische Kolonialregime umzustürzen - wurde gefangengenommen, Bolívar seinerseits konnte fliehen.

Wir können nun den weiteren, recht komplizierten Verlauf der Unabhängigkeitskämpfe im Allgemeinen und des Engagements Bolivars im Besonderen nicht weiter detailliert bis zur Schlacht von Ayacucho im Jahre 1824 verfolgen und würdigen. Diese berühmte Schlacht brachte letztlich die Entscheidung bezüglich des Endes der kolonialspanischen Herrschaft. Im Rahmen dieser Vorlesung werden wir weder auf die sich 1805 beziehungsweise 1806 abspielenden Ereignisse der Befreiung von Buenos Aires von Engländern durch kreolische Milizen (was deren Selbstverständnis stärkte) eingehen noch auf den bald schon blutig niedergeschlagenen Aufstand von Hidalgo und später Morelos in Mexiko. Die Militärkampagnen von San Martín im Süden des Kontinents, die sich parallel zum Unabhängigkeitskampf Bolívars entwickelten, können ebenfalls nicht Gegenstand unserer Untersuchung sein: Sie sollten lediglich erwähnt werden. Doch bildete all dies zweifellos den Hintergrund sowohl für die politisch-militärischen Strategien Bolivars wie auch seiner Einsicht in die künftigen Möglichkeiten der sich vom spanischen Kolonialismus befreienden Vizekönigreiche und „Audiencias“.

Hinzugefügt sei, dass es nach dem Eintreffen der Nachricht von der Besetzung Spaniens durch französische Truppen ab 1808 mehrfach Aufstände und kleinere Erhebungen gab. In Neuspanien besaß 1810 Hidalgos „Grito de Dolores“ den Charakter einer Volkserhebung, wobei sein Aufstand die herrschende Sozialordnung radikal in Frage stellte. Aus eben diesem Grunde wurde er von den Kreolen bekämpft, unterlag und wurde nach wenigen Monaten bereits ermordet. Sein Nachfolger Morelos versuchte, den von ihm organisierten Aufständen einen stärker gegen Spanien und die „Peninsulares“ gerichteten Anstrich zu geben. Doch findet sich auch bei ihm eine klar sozialrevolutionäre Tendenz; so wird auch Morelos im Jahr 1815 ermordet. Bei den von Hidalgo und Morelos angeführten Erhebungen handelte es sich um Bewegungen, die aus dem bäuerlichen Milieu kamen und gerade die herrschenden Sozialstrukturen angriffen, eine Tatsache, die mit den Absichten der neuspanischen Kreolen nicht in Einklang zu bringen 
war. Diese suchten letztlich erfolgreich, einen radikalen Umsturz zu konterkarieren, lediglich die Herrschaftsspitze auszutauschen und als Führungselite nunmehr von Spanien ungestört - die Macht auszuüben.

Mit den Interessen der Kreolen verträglicher war in Neuspanien die Ausgangsposition Iturbides, der seinerseits sehr wohl kreolische Ansprüche vertrat und in erstaunlich kurzer Zeit die Befreiung von kolonialspanischen Strukturen durchsetzen konnte, ohne freilich in grundlegender Weise an den Sozialstrukturen Mexikos zu rütteln. Iturbide erhob sich 1821 und konnte schon wenige Monate später erfolgreich in der Hauptstadt Mexikos einmarschieren. 1822 ließ er sich zum Kaiser krönen, ein weiterer Beleg dafür, wie präsent das französische Beispiel Napoleons war, das den Weg von einer Revolution in ein neues Kaisertum aufzeigte. Eine ganze Reihe in Auftrag gegebener Gemälde zeigt die Krönung Iturbides zum Kaiser: Sie zeugen davon, wie sehr alles dem napoleonischen Prunk und wie selbst der gesamte Habitus dem kaiserlich-französischen Vorbild nachempfunden war.

Dennoch sollten wir auch an dieser Stelle vorsichtig sein, zeigt sich doch eine Art Doppelcodierung, da Iturbide explizit zugleich an Anáhuac, das aztekische Reich der Mexica, anknüpfte und daher der kaiserlichen Symbolik mit ihren imperialen Adlern noch eine zweite Dimension zu Grunde lag. Iturbide handelte hierbei freilich aus Kalkül, war er doch bestrebt, die indigene Bevölkerung mit seiner Sache zu verbinden, um innenpolitisch die Hände frei zu haben. In der Area von Mexiko wie auch anderswo im ehemaligen Kolonialreich waren die Kreolen zwar an einer politischen Revolution im Sinne einer Abkehr von Spanien, nicht aber an der grundsätzlichen Veränderung etwa sozialer Hierarchien und vor allem von Besitzverhältnissen oder Produktionsketten interessiert.

All dies mag die klare Zurückhaltung der indigenen Bevölkerung wie teilweise auch der schwarzen Sklaven erklären, wobei letztere in den Unabhängigkeitskampf auf Seiten der Independentistas dort eingriffen, wo man ihnen als Gegenleistung das Ende ihrer Versklavung versprach. Die Independencia legte also keineswegs die Grundlage für wirklich erneuerte Gesellschaftsstrukturen, wie wir sie zeitgleich etwa in den wirtschaftlich entwickelteren Ländern Europas - zum Beispiel in Großbritannien oder Frankreich - vorfinden können. Auf die Bedeutung der schwarzen wie der indigenen Bevölkerung und der mit ihnen verbundenen kulturellen Pole wird am Beispiel vieler literarischer Texte, welche in unserer Vorlesung behandelt werden sollen, aber noch ausführlich zurückzukommen sein.

Durch den Fortgang der Ereignisse in seinem damaligen Vaterland, dem heutigen Venezuela, trat eine weitere Radikalisierung Bolivars bezüglich seiner Haltung zu Spanien ein. Er insistierte auf einer Einheit der Kreolen gegenüber Spanien sowie auf der notwendigen Disziplinierung und Sammlung militärischer Kräfte, um eine Entscheidung auf dem Schlachtfeld herbeiführen zu können. Dies war ein Gedanke, 
der nicht nur sehr häufig bei Bolivar selbst, sondern auch bei späteren Denkern Lateinamerikas - etwa bei José Martí - wiederkehren sollte: der Gedanke an die Einheit dessen, was der Kubaner entschieden als „Nuestra América“ bezeichnete. Doch eine politische oder zumindest wirtschaftliche oder soziale Einheit ist, wie wir wissen, aus dem zerfallenen kolonialspanischen Reich bis heute nicht wieder entstanden: Es gibt weder eine ,Lateinamerikanische Union“ noch existieren die ,Vereinigten Staaten von Lateinamerika' auf unseren Landkarten.

Bolivars Zielstellung der Schaffung einer Einheit der ehemals separat an Spanien angebundenen Kolonien wird etwa in seinem berühmten Manifiesto de Cartagena von 1812 deutlich erkennbar. Nach Cartagena de Indias hatte sich Bolivar über Caracas und Curaçao geflüchtet: Seine Lage war alles andere als erfolgversprechend. Ich möchte Ihnen gerne Anfang und Schluss von Bolivars Ansprache und Aufruf an die Bewohner Neugranadas vorlegen:

\begin{abstract}
Neugranada vom Schicksal Venezuelas zu befreien und letzteres von dem zu erlösen, was es erleidet, sind die Ziele, welche ich mir in dieser Denkschrift gesetzt habe. Oh meine Landsleute, lasst Euch dazu herbei, sie mit Blick auf so lobenswerte Ziele mit Nachsicht anzunehmen.

Ich bin, Ihr Granadiner, ein Sohn des unglücklichen Caracas, der inmitten der physischen und politischen Ruinen seiner Heimatstadt wunderbarerweise zu entfliehen vermochte, immer treu dem liberalen und gerechten System ergeben, welches mein Vaterland proklamierte, und so bin ich gekommen, den Standarten der Unabhängigkeit, welche sich so ruhmreich in diesen Staaten in die Höhe recken, hierher zu folgen.
\end{abstract}

[...]

Die Ehre von Neugranada macht es zwingend erforderlich, diesen waghalsigen Invasoren eine Abfuhr zu erteilen und sie bis hinein in die letzten Verschanzungen zu verfolgen, so wie der Ruhm Neugranadas davon abhängt, jene Unternehmung in die Tat umzusetzen, nämlich nach Venezuela zu marschieren, um die Wiege der kolumbianischen Unabhängigkeit, jene Märtyrer und jenes hochverdiente Volk von Caracas zu befreien, dessen Rufe sich allein an die geliebten Landsleute, die Granadiner, richten, welche sie als Erlöser mit einer tödlichen Ungeduld erwarten. Beeilen wir uns, die Ketten jener Opfer zu zerbrechen, welche in den Verließen stöhnen, stets von Euch ihre Errettung erhoffend: Enttäuscht ihr Vertrauen nicht: Steht den Wehklagen Eurer Brüder nicht empfindungslos gegenüber. Eilt geschwind, den Toten zu rächen, dem Sterbenden Leben zu geben, dem Unterdrückten Raum und allen die Freiheit zu schenken.

Cartagena de Indias, 15 . Dezember 1812. ${ }^{76}$

In diesen Passagen tritt uns die rhetorische Begabung des künftigen Libertador anschaulich vor Augen. Man spürt in dieser Rede nicht nur seine Entschlossenheit, ein für alle Mal die spanische Kolonialherrschaft zu beenden, sondern auch

76 Bolívar, Simón: Escritos políticos, S. 47 u. 57. 
seine Belesenheit gerade in der Revolutionsrhetorik, die sich in Frankreich nur wenige Jahrzehnte zuvor entwickelt und besonders blumig ausgebildet hatte. Versuchen wir, José Joaquín Fernández de Lizardi, Fray Servando Teresa de Mier und Simón Bolívar in eine Reihe zu stellen! Wir können feststellen, dass der erste vorübergehend im Gefängnis landete, um später seinen Kampf in gemäßigter, zu Kompromissen bereiter Form fortzuführen, und dass der zweite seine häufigen Gefängnisaufenthalte immer wieder durch erfolgreiche Ausbruchsversuche überwinden konnte und damit - wie Lezama Lima sagte - zum ersten „escapado“ in Amerika wurde, der sich durch die ständigen Verfolgungen zusätzlich noch radikalisierte. Der dritte schließlich stellte sich gleich zu Beginn als jenen dar, der den Kerkern der Tyrannei entflohen ist und nun den offenen, revolutionären Kampf mit seinen Verfolgern aufnimmt. Wir haben in diesen drei literarisch-politischen Figuren drei Reaktionsweisen, aber auch drei Perspektiven auf eine Unabhängigkeitsbewegung vor uns, welche die ganze Breite dieses Ausgangs weiter Regionen Amerikas aus der Kolonialzeit verdeutlichen.

Dabei erscheint mir wichtig, auf welche Weise Bolivar nun die verhassten Spanier apostrophiert: Er bezeichnet sie als ,invasores“, als Eindringlinge. Er tut dies so, als ob der Schnitt zwischen Amerikanern und Spaniern ganz leicht zu ziehen wäre, als ob es ein angestammtes Recht der Kreolen, also der in Amerika geborenen Nachfahren der Spanier, auf dieses Land gebe, das von einer fremden Macht widerrechtlich bedroht würde. Die spanische Herkunft der Kreolen wird hier nicht diskutiert, ja nicht einmal erwähnt. Es wird nicht ausgeführt, dass der Riss durch viele Familien selbst geht und nicht selten die Eltern von den Kindern trennt. Ja, es bleibt unausgesprochen, dass sich viele Spanier politisch, wirtschaftlich oder wissenschaftlich höchst verdient um die Kolonien gemacht hatten. Es geht Bolivar vielmehr um die patriotische Sammlung aller militärisch nutzbaren Kräfte, und da helfen keine störenden Differenzierungen, sondern nur die rhetorisch geschickten Bestimmungen eines klaren Feindbilds.

Aufschlussreich ist in dieser Passage - die im Übrigen auch auf das symbolträchtige Erdbeben von Caracas anspielt - des Weiteren, wie eine christliche Rhetorik der Erlösung und Märtyrerschaft für die säkularisierten Ziele der Independencia verwendet wird. Das ist, wenn wir uns die französische Revolutionsrhetorik anschauen, keineswegs neu; und doch wird sich im hispanischen Amerika eine sehr eigene Tradition an diese christliche Rhetorik anknüpfen. Bevor ich später noch auf diesen Punkt ausführlicher eingehe, sei jedoch noch erwähnt, wie die Independencia in gewisser Weise anthropomorphisiert wird, besitzt sie doch eine Wiege und damit eine Geburtsstunde, mit welcher der Name Bolívars in fundamentaler Weise verbunden ist.

Denn in einer auffälligen Personalisierung heftet der venezolanische Großgrundbesitzer von Beginn an seinen Namen an die Geschichte und Ausprägung 
der Unabhängigkeitsrevolution, die in Venezuela entstanden sei, nun aber ins Herz von Neugranada überspringen müsse. Damit verknüpft der künftige Libertador nicht nur sein Schicksal mit der Independencia; denn umgekehrt wird diese nun zu seinem eigenen Geschöpf. Damit deutet sich bereits die weitere Entwicklung des Mythos Bolívar an, deren grundsätzlich heroisch-agonisches Moment noch heute etwa in den politischen Rhetoriken Venezuelas offenkundig ist. Gerne erinnere ich mich an dieser Stelle an einen Besuch in der venezolanischen Hauptstadt Caracas, wo unweit der Statue Bolivars eine kleine Schule bestand, in welcher einst im Exil der Kubaner José Martí unterrichtet hatte. Heute ist aus dem Gebäude ein kleines Museum geworden, in welchem mit Hilfe einer Reihe heroischer Büsten eine gerade historische Linie gezogen wird von Simón Bolívar über José Martí und Fidel Castro hin zu Hugo Chávez. Bei ihnen allen ist im politischen Diskurs ein agonales rhetorisches Element - ein „Patria o Muerte“, ein „Socialismo o Muerte“ - deutlich vernehmbar.

Der venezolanische Historiker Germán Carrera Damas ${ }^{77}$ hat sich wie der deutsche Michael Zeuske ${ }^{78}$ intensiv mit dieser überaus wichtigen Seite des Bolívar-Kults auseinandergesetzt. Er betonte dabei, dass der Mythos rund um Simón Bolivvar als solcher in Venezuela bis heute eine überaus wichtige ideologische Form sei, die auch zur Allpräsenz Bolivars im politischen wie im Alltagsleben Venezuelas geführt habe. Es sei nicht zuletzt die Historiographie gewesen, die den Bolivar-Kult aufgebaut habe, der sich in der Wiederholung der immer selben Zitate, aber auch in einer Sakralisierung des „Héroe“ und „Libertador“ massiv zu äußern pflege: Die Verehrung für den Befreier Südamerikas nehme dabei durchaus die Züge und Formen von Heiligenviten und Heiligenlegenden an.

Schon José Antonio Páez Herrera, der Simón Bolívar zu Lebzeiten bekämpft hatte, erkannte die quasi mythologische Wichtigkeit dieser historischen Figur und beteiligte sich an der gezielten Monumentalisierung des Libertador. Germán Carrera Damas lokalisierte den Beginn des Bolivar-Kults in der Romantik, verwies aber darauf, dass dieser Kult ganz bestimmte gesellschaftliche Funktionen übernommen habe, die insbesondere in der Verschleierung des soziopolitischen Versagens der venezolanischen „burguesía terrateniente“, der Großgrundbesitzerschicht, gelegen habe. ${ }^{79}$ Die Berufung auf Bolivar ersetzte nicht selten fehlende politische Programme.

77 Vgl. Carrera Damas, German: El culto a Bolivar. Esbozo para un estudio de la historia de las ideas en Venezuela. Caracas: Instituto de Antropología e Historia 1969.

78 Vgl. Zeuske, Michael: Simón Bolívar, Befreier Südamerikas. Geschichte und Mythos. Berlin: Rotbuch Verlag 2011.

79 Vgl. Carrera Damas, Germán: El culto a Bolivar, S. 42. 
Simón Bolívar diente, wie dies bei so vielen großen politischen Figuren bis heute in Lateinamerika der Fall ist, allen politischen Lagern als Bezugspunkt und Legitimationsfigur. Seit der Repatriierung von Bolivars Leichnam unter großem Pomp im Jahre 1842 kam es zu einer zunehmenden Vergöttlichung Bolivars, den als Gott, als „Dios“ zu bezeichnen man sich auch nicht scheute. ${ }^{80}$ Bereits Carrera Damas hat recht aufwendig nachgewiesen, wie es zu einer ganz bewussten Konstruktion des Kultes kam und wie sich - wie er es ausdrückte - innerhalb des Kultes Priester und Oberpriester etablierten, welche die Lehre von Reinheit und Idealität verbreiteten. Die Institutionalisierung des Bolívar-Kultes wird von Bolívar-Vereinigungen und Bolívar-Lehrstühlen, aber auch einer Vielzahl von Monumenten und Büsten, von seinen Feiertagen wie Geburtstag und Todestag geprägt. Es ist dies eine Entwicklung, die nur noch einer weiteren Figur im hispanoamerikanischen 19. Jahrhundert zuteilwerden sollte: José Martí, dessen Aktualität bis heute ungebrochen ist und der noch immer von den verschiedensten politischen Lagern für sich reklamiert wird. ${ }^{81}$ Martí diente ebenso den so unterschiedlichen Politikern Fulgencio Batista wie Fidel Castro, aber auch deren Gegnern als Legitimationsfigur.

Dabei gilt für Bolívar wie Martí, dass sie für ihre jeweiligen Nationen und Bevölkerungen zu Identitätsfiguren und -trägern geworden sind und daher - oft jenseits ihrer Schriften und eher in einem Bereich der Imagologie - essentielle gesellschaftliche Funktionen übernahmen. Kritik an Bolivar zu äußern ist, wie Jürgen von Stackelberg unterstrich, ${ }^{82}$ längst zu einem Sakrileg geworden. Von Stackelbergs Anmerkung aus den achtziger Jahren des zurückliegenden Jahrhunderts kann man getrost unter den aktuellen politischen Verhältnissen in Venezuela als Untertreibung werten. Simón Bolivars Figur ist nicht nur volkskulturell, sondern auch literarisch zu einem Mythos geworden, an dem gerade lateinamerikanische Autoren wie José Martí, Miguel Angel Asturias, Pablo Neruda oder Gabriel García Márquez weiterarbeiteten. Denn bei diesen Autoren präsentiert sich Bolívar, der sehr wohl die Interessen einer ganz bestimmten, nämlich oligarchischen Gesellschaftsgruppe vertrat, allen Widersprüchen zum Trotz als ein ,Messias der Freiheit'.

80 Vgl. ebda., S. 61.

81 Vgl. hierzu die Dissertation von Ette, Ottmar: José Martí. Teil I: Apostel - Dichter - Revolutionär. Eine Geschichte seiner Rezeption. Tübingen: Max Niemeyer Verlag (Reihe mimesis, Bd. 10) 1991.

82 Vgl. Stackelberg, Jürgen von: Der Mythos vom Befreier. Anmerkungen zu Simón Bolívar. In: Romanistische Zeitschrift für Literaturgeschichte (Heidelberg) 6 (1982), S. 24-44. 
Kehren wir aber nach Erörterung der historischen Gestalt und des politischen wie literarischen Mythos zu den Schriften und Texten Simón Bolívars zurück, auch wenn der Mythos zweifellos Teil seines Werkes - in einem rezeptionsästhetischen Sinne - war und bleibt. Zusätzlich zu den bereits dargestellten Aspekten tritt mit Bolívar die Kunst der Rede, ja genauer noch: die Revolutionsrhetorik, ein in die auch literarischen Traditionen des Subkontinents. Die revolutionäre Oratorik wird im 19. Jahrhundert von größter Bedeutung nicht nur für die Geschichte, sondern auch für die Literaturen in Lateinamerika sein - denken wir nur neben den politischen Reden eines José Martí auf Ebene einer Schulrhetorik beziehungsweise der Tradition akademischer Reden an José Enrique Rodó und seinen mit dem neuen Jahrhundert veröffentlichten Ariel: Auch im 20. Jahrhundert wird diese Tradition keineswegs an Stärke verlieren und stets auf die wie auch immer säkularisierten christlichen Elemente zurückgreifen: Fidel Castros Verteidigungsrede La historia me absolverá signalisiert diese Verbindung von christlicher Symbolik und Rhetorik mit der Revolution in einem agonalen Tonfall bereits im Titel. Die politische Oratorik gehört zum Kernbestand einer durchaus auch literarischen Öffentlichkeitsstruktur in Lateinamerika.

Die Konsolidierung und Verstärkung der independentistischen Truppen wird von Bolivar erfolgreich bewerkstelligt, was in der Folge zu einer Reihe von Siegen über die Spanier im Hinterland von Cartagena de Indias, bald aber schon in ganz Nueva Granada führt. Am 6. August 1813 reitet Bolivar als triumphaler Sieger in Caracas ein. Um die Fehler der Ersten Republik zu vermeiden, führt er eine zentralistische Straffung ein und herrscht auf fast diktatorische Weise auf Basis der Vollmachten, welche ihm die Vollversammlung, die „Asamblea Representativa“, an die Hand gab. Es mag durchaus sein, dass sich in diesen ,Ermächtigungsgesetzen' etwas von jener Tendenz zum Autokratischen andeutete, das der Argentinier Sarmiento 1845 in seinem Facundo so heftig kritisierte und zugleich in die Literaturgeschichte des Kontinents einbrachte. Dass er dabei nicht der Erste war, werden wir im anschließenden Kapitel zu Esteban Echeverría noch genauer untersuchen.

In jedem Falle wies Domingo Faustino Sarmiento mit guten Gründen darauf hin, dass es nicht angehen könne, Bolívar wie einen europäischen General darzustellen, wie dies in zahllosen Lexikonartikeln geschehe. Es handle sich - ganz im Gegensatz zu San Martín, der in seinem Auftreten, aber auch in der Ordnung seiner militärischen Aktionen ein perfekter Europäer sei - bei Bolívar vielmehr um einen Amerikaner mit höchst amerikanischem Gesellschaftshintergrund. Just an diesem Ort seiner Argumentation stellte Sarmiento, auch aus durchaus nationalistisch interessierter Seite, den Sohn der „Llanos“ in eine Entwicklungsreihe mit den späteren „Caudillos“ auf dem Lande, die für Sarmiento die europäische Zivilisation bekämpft hätten. Nun, so weit würde ich nicht gehen! Denn Bolívar 
ist zweifellos mehr als ein ländlicher „Caudillo“, dem es allein um die absolute Herrschaft, um direkte Macht und Gewalt, gegangen wäre. Er ist allerdings auch nicht allein nach europäischen Maßstäben und mit europäischen Vorstellungen als General zu beschreiben, da hat Sarmiento schon Recht! Bolívar entwickelt vielmehr - wie wir gleich sehen werden - eine Vielzahl amerikanischer Visionen: Er ist eine der großen Figuren, denen es gelang, jenseits des jahrelangen und oftmals desillusionierenden Kampfes gegen die spanische Kolonialherrschaft leitende Zielvorstellungen zu entwickeln, die uns noch im 20. und 21. Jahrhundert begleiten werden.

Die unversöhnliche Haltung gegenüber den Spaniern und Kanaren, die sich nicht eindeutig zur Unabhängigkeit Amerikas bekennen, wird von Bolívar und seinen Anhängern konsequent fortgesetzt. Eine brutale Auseinandersetzung zwischen beiden Seiten, dem „Ejército independentista“ wie dem „Ejército realista“, ist die unmittelbare Folge. ${ }^{83}$ In beiden Heeren kämpfen Venezolaner. 1814 freilich unterliegen die Truppen Bolivars: Valencia und Caracas fallen in die Hände des „Königlichen Heeres“, des „Ejército realista“ und seiner Reiter. Damit endet die Zweite Republik, Bolívar flüchtet nach Barcelona und schließlich erneut nach Cartagena de Indias. Nach einer Reihe von Erfolgen in Nueva Granada muss er sich zudem mit Widersachern im eigenen Lager und deren Verleumdungen auseinandersetzen.

Darüber hinaus wurde die Situation für die Anhänger der Unabhängigkeit dadurch gefährlich, dass ein aus elftausend Soldaten bestehendes Heer aus Spanien in Amerika eintraf. Im Dezember 1814 wurde Cartagena de Indias von den Spaniern besetzt; Bolívar flüchtete im Mai 1815 nach Jamaica, finanziell ruiniert, da die Spanier seinen Besitz enteignet hatten. Vergeblich bemühte er sich von Jamaica aus um die Unterstützung seiner Pläne durch die britische Regierung.

Aus diesem für den Libertador schwierigen Zeitraum stammt die berühmte sogenannte Carta de Jamaica, die Bolívar auf den 6. September 1815 in Kingston datierte. Sie ist von grundsätzlicher Bedeutung für ein Verständnis des Lebenswerks Bolivars, zeigt seine Visionen der politischen Zukunft, kulturellen Identitätsfindung und anzustrebenden Einheit der vom Kolonialismus noch zu befreienden Regionen. Eben deshalb wollen wir uns mit dieser Carta de Jamaica ausführlicher beschäftigen, erschien sie doch zu einem Zeitpunkt, als alles ausweglos schien und die Spanier mit der Rückeroberung ihres Kolonialreiches beschäftigt waren. Es handelt sich - so der ursprüngliche Titel - um die Contestación de un Americano meridional a un caballero de esta isla, um die Antwort eines Südamerikaners an einen Herrn von dieser Insel, womit Bolívar eine literari-

83 Carrera Damas, Germán: El culto a Bolivar, S. 7. 
sche Form, den Brief, sowie eine Perspektive wählte, die einem Außenstehenden, einem Jamaikaner die Ereignisse und Möglichkeiten Hispanoamerikas vorgegebenermaßen zu erklären sucht.

Im Rückgriff auf Bartolomé de Las Casas und Alexander von Humboldt, aber auch auf die sogenannte „Leyenda negra“, die ausgehend von Las Casas’ Streitschrift der Brevísima relación de la destrucción de las Indias Spanien als Urheber aller Barbareien und des gigantischen Völkermordes an der indigenen Bevölkerung in Amerika brandmarkte, entwirft Bolívar in diesem fingierten Brief seine eigenen Konzeptionen und Visionen. Dabei ist der Bruch mit Spanien unwiderruflich:

Dies Ereignis würde unsere Bemühungen krönen, denn es legte das Schicksal Amerikas unwiderruflich fest; die Bande, welche Amerika mit Spanien verbanden, sind durchschnitten: Die vorherrschende Meinung war deren ganze Kraft; durch sie rückten die Teile jener unermesslichen Monarchie einander wechselseitig näher; doch was sie vorher verband, teilt sie nun; größer ist der Hass, den uns die Iberische Halbinsel bislang einflößt, als das Meer, das uns von ihr trennt; weniger schwierig ist es, die beiden Kontinente zu vereinen, als die Spanier beider Länder wieder miteinander zu versöhnen. [...] Alles erlitten wir von dieser ihrer eigenen Natur entfremdeten Stiefmutter. Der Schleier ist zerrissen, wir haben das Licht schon gesehen, und man will uns in die Finsternis zurückstoßen; die Ketten sind zerrissen; wir waren bereits frei, doch unsere Feinde versuchen noch immer, uns erneut in die Sklaverei zu führen. ${ }^{84}$

Simón Bolivar führt hier sein manichäistisches Schema fort in rhetorischen Formulierungen, die rasch berühmt werden sollten und definitiv die Abkoppelung Amerikas von Spanien in prägenden Bildern beschworen: Nichts scheint die ehemaligen Kolonien noch mit ihrem sogenannten Mutterland zu verbinden. Zugleich bemüht Bolívar die Lichtmetapher für das Reich der Freiheit, das sich in Amerika verkörpert, dem das Reich der Finsternis, für welches Spanien steht, entgegengestellt wird. Dies ist ganz so, wie Spanien etwa bei den französischen Aufklärern als Reich der Finsternis und Tyrannei sowie Feind von Aufklärung und menschlicher Vernunft galt, wie etwa in den Formulierungen Montesquieus: Spanien als „ennemi du genre humain“, als Feind der Menschheit überhaupt.

Die abschließende metaphorische Rede von der Versklavung ist darüber hinaus insoweit bedeutungsvoll, als in diesen Wendungen die Sklaverei weniger auf die reale Versklavung der Schwarzen - die Bolívar in der Zukunft gewiss nicht aus den Augen und aus seinem politischen Kalkül verlor - bezogen wird. Denn auch Bolívar hatte bis zu seiner Enteignung wie alle großen „Hacenderos“ und

84 Bolívar, Simón: Escritos políticos, S. 63. 
„Terratenientes“ Sklaven auf seinen Plantagen und Gütern besessen und kein Problem in der Versklavung eines nicht geringen Teiles der Bevölkerung gesehen. Vielmehr wird die Sklaverei in diesen Formulierungen politisch-metaphorisch verstanden, so wie sie etwa auch in Europa - speziell im Frankreich der Revolution - begriffen werden konnte, wo es freilich keine im ursprünglichen Wortsinn als solche beschreibbare Sklaverei (mehr) gab.

Simón Bolívars Oratorik ist in diesen rhetorischen Wendungen revolutionär und konservativ zugleich. Konservativ ist sein Standpunkt in einem doppelten Sinne: zum einen, weil die eigene problematische Situation der Sklaverei nicht selbstkritisch ins eigene Denken miteinbezogen wird. Dies geschieht gewiss auch aus dem Bewusstsein heraus, dass die reichen Kreolen, auf deren Unterstützung Bolívar angewiesen war, keinesfalls mit einer raschen Abschaffung der Sklaverei einverstanden sein konnten. Zum anderen ist sie konservativ, weil in diesen Wendungen eine traditionelle Rhetorik übernommen wurde, ohne dass ihre manichäistische Metaphorik - Licht versus Finsternis, Mutterland beziehungsweise Stiefmutter versus stolze Söhne, Sklaverei versus Freiheit -, aber auch ihre diskursiven Grundstrukturen wie auch ihre Bilder und Metaphern einer grundlegenden und kritischen Überprüfung zugeführt worden wären. Zugleich aber ist in dieser Passage allen Verankerungen in einer revolutionär-aufklärerischen Rhetorik zum Trotz ein neuer, romantischer Gestus einer stolzen Befreiung aus alten Verhältnissen zu spüren, welcher das Werk der Independencia vielfach in ein von der Aufklärung abgetrenntes idealisiertes Licht zu rücken vermochte. Simón Bolívar war in diesem Sinne auch ein Held, eine Gestalt neuen Typs.

Der Libertador verweist mehrfach auf die riesige Ausdehnung der Hemisphäre und beurteilt die Entwicklung des Unabhängigkeitskampfes in den verschiedenen Regionen der hispanoamerikanischen Welt bei allen Unterschieden durchaus optimistisch. Sein Augenmerk widmet er besonders dem Río de la Plata, dem „Reino de Chile“, dem „Virreinato del Perú“ sowie „Nueva Granada“ und „Nueva España“, 85 ohne freilich darüber die Antillen und vor allem die Wiege der Revolution, „la heroica y desdichada Venezuela“, zu vergessen. Das Wissen Bolívars über Amerika ist bemerkenswert, seine Weitsicht schlicht bewundernswert. „Sechzehn Millionen Amerikaner verteidigen ihre Rechte“ ${ }^{86}$ so lautet die Zusammenfassung seines Überblicks, der mit Verweisen auf Humboldt, Walton und Raynal garniert ist. Es läge zwar im Interesse des zivilisierten Europa, den bedrängten Südamerikanern zu Hilfe zu eilen, doch würden weder die Europäer

85 Ebda., S. $63 \mathrm{ff}$.

86 Ebda., S. 65. 
noch „nuestros hermanos del norte“, die US-Amerikaner, ${ }^{87}$ ihre Hilfe im Kampf anbieten. Was wird die Zukunft den riesigen Kolonien Spaniens bringen? Was wird das Schicksal der Neuen Welt und ihrer hoffnungsvollen Bewohner sein?

Es ist noch schwieriger, das künftige Schicksal der Neuen Welt vorherzusagen, Prinzipien bezüglich seiner Politik zu etablieren und gleichsam die Natur seiner Regierung zu prophezeien, welche es einmal übernehmen wird. Jede auf die Zukunft dieses Landes gerichtete Idee scheint mir gewagt. Konnte man es denn vorhersehen, als das Menschengeschlecht sich noch in seiner Kindheit befand und von so viel Unsicherheit, soviel Ignoranz und so vielen Irrtümern umgeben war, welches die Regierungsform sein könnte, die es für seine Selbstbewahrung einmal wählen würde? Wer hätte es damals gewagt zu sagen, welche Nation eine Republik und welche eine Monarchie, ja dass dieses Land einmal klein und jenes andere groß sein werde? Nach meinem Dafürhalten ist dies aber das Bild unserer Situation. Wir sind ein kleines Menschengeschlecht; wir besitzen eine eigene Welt; wir sind von weiten Meeren umgeben, neu in fast allen Künsten und Wissenschaften, und doch auf eine gewisse Art alt in den Gebräuchen der Zivilgesellschaft. Ich halte den aktuellen Zustand von Amerika für vergleichbar mit jenem Augenblick, als das Römische Reich zusammengebrochen war und jede Abspaltung ein politisches System ergab, in Übereinstimmung mit den jeweiligen Interessen und der Lage, aber auch in Abhängigkeit von den besonderen Ambitionen mancher ihrer jeweiligen politischen Führer, Familien oder Korporationen; mit dem bemerkenswerten Unterschied freilich, dass jene verstreuten Glieder ihre alten Nationen mit jenen Veränderungen wiederherstellten, welche die Dinge oder die Ereignisse erforderlich machten; wir aber, die wir kaum noch die Trümmer dessen bewahren, was in einer anderen Zeit einmal war, und die wir auf der anderen Seite weder Indianer noch Europäer sind, sondern eine mittlere Spezies zwischen den legitimen Eigentümern des Landes und den spanischen Usurpatoren darstellen: Wenn wir alles zusammengenommen folglich Amerikaner durch Geburt und unsere Rechte die von Europa sind, so müssen wir diese mit jenen des Landes konfrontieren und gegen die Invasion der Invasoren aufrecht erhalten; so befinden wir uns in dem außerordentlichsten und kompliziertesten Falle; dessen ungeachtet ist es eine Art Weissagung, wollte man angeben, welches das Ergebnis der politischen Linie sein könnte, welche Amerika einschlagen wird, und doch will ich es wagen, einige Vermutungen zu äußern, welche ich selbstverständlich für arbiträr halte, sind sie doch von einem rationalen Wunsche und nicht von einer Wahrscheinlichkeitsrechnung diktiert. ${ }^{88}$

In dieser langen und zugleich rhetorisch sehr verdichteten Passage der Carta de Jamaica finden sich entscheidende Fragestellungen und Lösungsansätze, die das gesamte 19. Jahrhundert Lateinamerika in grundlegender Weise bestimmen werden. Die Verwendung des Begriffs „Neue Welt“ ist hier erkennbar bewusst gesetzt, denn neu ist diese Welt im Sinne Bolívars nicht etwa deshalb, weil sie später und von der sogenannten,Alten Welt‘ aus entdeckt worden wäre, sondern

87 Ebda., S. 67.

88 Ebda., S. $69 \mathrm{f}$. 
weil sie keine Modelle und Vorbilder besitzt, auf die sie sich berufen könnte, keine Staatswesen und Einrichtungen, an denen sie sich orientieren sollte. Die Zukunft, so könnten wir sagen, ist radikal offen. Und sie ist es zu diesem historischen Zeitpunkt für den amerikanischen Kontinent noch radikaler, weil dieser auf seinem Boden über keine Vorbilder verfügt, an denen man die künftige Entwicklung ausrichten könnte, sind doch die indigenen Reiche, von denen nur noch Trümmer vorhanden seien, als vorbildgebende Strukturen für die lateinamerikanischen ,Gründungsväter ' der kreolischen Elite gänzlich unvorstellbar.

Mit Hilfe unserer Überlegungen im ersten Teil dieser Vorlesung können wir dies weltgeschichtlich wie globalphilosophisch präziser einordnen: Denn Geschichtswissenschaftler und Philosophen haben in den vergangenen Jahrzehnten aufgezeigt, dass erst im Umkreis der Französischen Revolution die Erfahrung um sich greift und auch breiter philosophisch reflektiert wird, dass die Zukunft politischer Systeme und der Menschheit insgesamt als offen gedacht werden muss und sich nicht an bereits existierenden Staatsformen $\mathrm{zu}$ orientieren hat. Dass Geschichte und deren Zukunft überhaupt als offen gedacht werden kann, ist eine historische Errungenschaft, die im Vorfeld der Französischen Revolution entstand und durch deren Ereignischarakter untermauert wurde. Die Überzeugung von der Zukunftsoffenheit von Geschichte ist ein Attribut der Moderne wie der je nach kultureller Area verschiedenen Auslegungen dieser Moderne.

Simón Bolivar überträgt die Einsicht in diese Zukunftsoffenheit auf Amerika, auf die Neue Welt, indem er deren Einwohner als ein ,kleines Menschengeschlecht` umschreibt und damit nicht nur im übertragenen Sinne eine Art eigene Welt konzipiert, die folglich auch ihre eigene Gesetzlichkeit („derechos“) und vor allem ihre eigene Zukunft haben werde. Amerika - und Bolivar versteht hierunter zunächst einmal die hispanoamerikanisch kolonisierten Bereiche, im weiteren Sinne aber durchaus die gesamte Hemisphäre - erscheint unter seiner Feder als eine Welt für sich, von weiten Meeren umgeben: fast wie eine Insel, die nach allen Seiten hin von Küsten gesäumt ist.

Die Konzeption eines einheitlichen, von anderen Bereichen der Welt aber unterschiedenen Amerika beginnt sich in diesen Zeilen herauszukristallisieren. Dies macht die Beantwortung der im Grunde essentialistischen Frage notwendig, wer die Bewohner dieser neuen Welt dann eigentlich sind oder sein sollten.

Der Begriff „Nuestra América“ wird hier mit Händen greifbar, zeigt sich doch auch bei Bolivar eine Identifikation mit diesem Teil der Erde, und ist seine Sichtweise doch auch die der aufgeklärten, von den Vorstellungen der französischen Aufklärung mitgeprägten kreolischen Führungsschicht. Stets spricht er hier in der ersten Person Plural, die keineswegs ein Pluralis majestatis ist, sehr wohl aber die kreolische Trägerschicht der Unabhängigkeitsrevolution verkörpert. Simón Bolivar gibt in seinen rhetorisch ausgefeilten Formulierungen vielmehr metapho- 
risch einem riesigen Gebiet und seinen Bewohnern Stimme: Sein „Wir“ steht für Amerika! Dass damit zugleich auch andere Stimmen ausgeschlossen werden, die wir in unserem Schema kultureller Pole identifizierten, sei an dieser Stelle nicht vergessen.

Dieser Entwurf von Identitätsfindungsprozessen der Bewohner dieses „mundo aparte“ ist durchaus originell, wenn auch noch tastend, suchend, bis in die Formulierungen hinein beweglich. Das Neue und das Alte kombinieren und verbinden sich in Amerika; und an dieser Stelle führt Bolívar ganz bewusst ein historisches Vorbild ein, vergleicht er doch den Zerfall des kolonialspanischen mit dem des Römischen Reiches, von dessen einzelnen Teilen niemand die jeweilige Zukunft habe voraussagen können. Wie sollte es zu seinem Zeitpunkt also möglich sein, die Zukunft genauer zu bestimmen und den Gang der Ereignisse vorauszusagen? War diese Zukunft denn nicht auf radikale Weise offen?

Mit diesen Überlegungen Bolívars jedoch wird zugleich und eher unbewusst ein weiterer Gedanke in den Text eingeblendet: Aus dem Zerfall des Römischen Reiches bildete sich keineswegs ein einheitliches, neues, zusammenhängendes Reich, sondern vielmehr ein Mosaik von Ländern und Gebieten heraus, die nie mehr zu einer wie auch immer gearteten Einheit zurückfanden. Gerade in diesem Sinne darf das Beispiel des Römischen Reiches kein Vorbild gebendes Exemplum sein. Und Bolívar wird einen großen Teil seiner Anstrengungen und seines politischen Lebens darauf verwenden, sich immer wieder aufs Neue gegen die doch unaufhaltsame Gefahr des Zerfalls der ehedem schon prekären Einheit der so verschiedenartigen Teilregionen Amerikas zu stemmen. War die Zukunft radikal offen, so war sie auch von Menschen gestaltbar; und Bolívars Zauberformel für diese künftige Gestalt(ung) hieß Panamerikanismus.

Daher auch die rhetorische Abgrenzung von diesem geradezu klassischen Beispiel mit „mas nosotros“: Der Vergleich wird also nicht zu Ende gedacht, er darf dem Leser nicht allzu schlüssig werden, funktioniert aber dennoch als Textsignal, das diese semantische Ebene eines drohenden Verfalls in den bolivarianischen Text einblendet. Die Beziehung wird gleichsam historisch gekappt, da ,wir in Amerika kaum Überreste und Denkmäler früherer Zeiten besitzen, so formuliert der Libertador. Dies könnte aus heutiger Zeit angesichts der Vielzahl erhaltener oder wieder freigelegter indigener Tempelbauten, Piktogramme oder Wegenetze als ebenso kühne wie unzutreffende Behauptung erscheinen. Doch müssen wir uns vor Augen halten, dass eine Vielzahl solcher Denkmäler noch nicht wieder gefunden, aus dem Reich der Natur wieder zurückerobert, geschweige denn in der adäquaten archäologischen und historischen Bedeutung wieder erfasst worden war.

Amerika war - wie Alexander von Humboldt es formulierte, mit dem im Grunde erst die Amerikanistik beginnt - zum damaligen Zeitpunkt noch immer 
eine neue Welt in dem Sinne, dass auf dem amerikanischen Kontinent nicht historische Bauwerke, sondern das Reich der Natur bei weitem dominiere. Erschien diese indigene Geschichte aber lediglich als eine Prähistorie, als eine VorGeschichte, von der den Menschen nur wenig bekannt war, dann kann diese Welt in der Tat - und so dürfte Bolívar diesen Begriff auch gemeint haben - als eine neue Welt verstanden werden: Als eine neue Welt, die man gestalten und nach den eigenen Vorstellungen modellieren konnte. Und in der Tat war entscheidend, wie sich die Geschichte in jenen drei Jahrzehnten zu Beginn des 19. Jahrhunderts entwickelte und welche Optionen sich eröffneten.

Was aber war mit den Menschen, die in dieser Welt leben? Die Antwort Simón Bolívars enthält diesbezüglich eine doppelte Abgrenzung. Denn die Bewohner dieser Welt, das kollektive „Wir“, das der Libertador verwendet, sind weder Indianer noch Europäer, sondern eine Art mittlere Spezies in der Menschheitsgeschichte. In diesem Zusammenhang ist erstaunlich, dass Bolivar die Indianer zu legitimen Eigentümern des Landes erklärt, denen er die spanischen Usurpatoren entgegenstellt. Seine Argumentation wirkt freilich weniger überraschend, wenn man begreift, dass daraus die aktuellen Besitzrechte gegen die jetzigen Invasoren abgeleitet werden - und zwar nicht für die indigene Bevölkerung selbst, sondern für die Kreolen als Trägerschicht einer neuen Epoche. Man könnte in dieser Argumentation Bolívars den Ausdruck einer Symbolpolitik, einen geschickten diskursiven Trick oder auch den Geburtsfehler der Independencia erkennen. Denn man wird gleichwohl zur Kenntnis nehmen müssen, dass mit den Kreolen eine gleichberechtigte Einbeziehung der indigenen Bevölkerungsgruppen zum damaligen Zeitpunkt - und sicherlich auch heute noch - nicht möglich war: Die neuen postkolonialen Besitzverhältnisse sollten sich in den nun ausgerufenen Republiken rasch zementieren.

Ohne zur indigenen Bevölkerung zu gehören, können die ,Amerikaner qua Geburt', die objektiv sehr wohl zur kolonialen Ausbeutung der amerikanischen Urbevölkerung beigetragen hatten und dieses Ausbeutungssystem nun postkolonial übernahmen, doch die rechtliche Nachfolge der Indianer antreten. Die „especie media“ ist freilich recht paradox formuliert: Handelt es sich um eine Vermischung, wie der Begriff „media“ nahelegen könnte? Oder dominiert vielmehr die Abgrenzung sowohl gegenüber der indigenen Bevölkerung als auch den spanischen Eroberern? Klar ist in dieser Passage vor allem, dass Bolívar für die Amerikaner gleichsam einen eigenen Bereich eröffnet, eine eigene Spezies einführt, die in sich wiederum als homogen begriffen wird. Diese Amerikaner sind freilich die Söhne und Töchter der Spanier sowie anderer europäischer Einwanderer. Und sie erheben Anspruch auf das Erbe der indigenen Bevölkerung und betrachten die Spanier, gleichsam ihre Eltern, als pure Invasoren. Diesen Widerspruch gilt es zu verstehen, will man einen großen Teil jener Probleme begreifen, welche die aus 
einer solchen Unabhängigkeitsrevolution entstandenen Gesellschaften bis heute mit sich herumschleppen.

Bolívar ist nur das Sprachrohr seiner Trägerschicht; und deren Ansinnen ist und bleibt für lange Zeit erfolgreich. In der von Bolívar erfundenen amerikanischen Spezies gibt es keine Spanier, aber auch - und das ist wichtig - keine Indianer, die ja diskursiv sehr wohl als eine Gruppe erscheinen, die einen deutlich älteren Rechtsanspruch auf diese Territorien geltend machen könnte. Werden die Indianer auch als rechtmäßige Herren dieses Landes dargestellt, so werden sie doch zugleich aus diesem Konzept getilgt oder zumindest an dessen Ränder verbannt. Die „especie media“, so scheint es, umschreibt letztlich doch nur den Standpunkt der Kreolen, die in der Tat zwischen Spaniern und Indianern stehen.

In den rhetorisch geschickten Wendungen Simón Bolívars handelt es sich mithin nicht, wie man meinen könnte, um die Formulierung einer mestizischen Identität, auch wenn einige sprachliche Versatzstücke in eine solche Richtung deuten, sondern vorrangig um die Formulierung einer kreolischen Identitätskonstruktion, welche zugleich einen Rechtstitel für diese ,Amerikaner beansprucht. Diese Identitätskonstruktion ist ohne jeden Zweifel vorrangig gegen die Spanier, gegen die noch auf ihr Recht pochende Kolonialmacht gerichtet und stützt sich vor allem aus rhetorischen Gründen auf indigene Ansprüche, die einverleibt werden. So zeigt sich an dieser Stelle bereits die ganze Ambivalenz und Begrenztheit der hispanoamerikanischen Unabhängigkeitsrevolution: Sie wird im Namen Amerikas und der in Amerika Geborenen unternommen, schließt aber keineswegs alle Amerikaner in ihre Vorstellungen ein, sondern grenzt ihrerseits weite Teile der Bevölkerung zum Wohle der kreolischen Machtelite diskret aus.

Bolívars Begründung der Erhebung gegen Spanien und vor allem sein Entwurf eines politischen Systems, in dem er der Föderation eine klare Absage erteilt, sollen uns an diesem Punkt unserer Vorlesung nicht näher interessieren. Aufschlussreicher ist sein Zukunftsentwurf für Nueva Granada, für das er den Namen „Colombia“ vorschlägt, zu Ehren des „creador de nuestro hemisferio“, des Schöpfers unserer Hemisphäre. ${ }^{89}$ Nur wenige Jahre werden im Übrigen vergehen, bis sein eigener Name an eine neu gegründete Republik im Bereich HochPerus, an „Bolivia“ ehrenhalber vergeben wird. Dass es just diese Republik ist, in welcher sich heute die indigene Bevölkerung erstmals mit einem eigenen Staatspräsidenten durchsetzte und indigenen Besitzstrukturen in indigen besiedelten Bereichen nach Jahrhunderten wieder Raum gab, erscheint als durchaus signifikant und nicht nur als eine Randnotiz der Geschichte. Auch hier ist freilich die Fortsetzung der Geschichte offen: Wird es möglich sein, polylogische Strukturen

89 Ebda., S. 79. 
in das Staats- und Gesellschaftssystem einzuführen und verschiedenen Rechtsund Besitzformen zugleich eine Legitimität zu verleihen?

Bolívar gab seiner Hoffnung Ausdruck, dass man die Wilden, „los salvajes“, bald werde zivilisieren können. Es ist die Hoffnung darauf, die indigene Bevölkerung gleichsam kulturell zum Verschwinden $\mathrm{zu}$ bringen, folglich $\mathrm{zu}$ akulturieren und als eigenen kulturellen Pol auszuschalten. Auch an dieser Stelle zeigt sich deutlich, dass die „especie media“ auf kultureller Ebene keineswegs eine Mischung aus indianischer und europäisch-abendländischer Welt darstellt, sondern gerade die abendländischen Muster der Ausgrenzung, der Diskriminierung, der Trennung zwischen den Wilden und den Zivilisierten übernimmt, die so alt ist wie die Eroberungsgeschichte des amerikanischen Kontinents. ${ }^{90}$ Derartige Vorstellungen fließen auch ein in die kulturell fundierten Überlegungen Bolivars zu einer Einheit Amerikas:

Es ist eine grandiose Idee, den Versuch zu unternehmen, aus der gesamten Neuen Welt eine einzige Nation mit Hilfe eines einzigen Bandes zu formen, das seine Teile wie auch das Gesamte zusammenhält. Da es einen Ursprung, eine Sprache, eine Sitte und eine Religion besitzt, sollte es folglich auch eine einzige Regierung haben, welche die verschiedenen sich herausbildenden Staaten konföderiert; doch ist dies nicht möglich, weil weit voneinander entfernte Klimate, verschiedenartige Situationen, entgegengesetzte Interessen und voneinander abweichende Charaktere Amerika trennen. Wie schön wäre es, wenn der Isthmus von Panamá für uns das wäre, was der Kontinent für die Griechen war! Hoffentlich haben wir eines Tages das Glück, dort einen verehrungswürdigen Kongress der Repräsentanten von Republiken, Königreichen oder Kaiserreichen zu installieren, um über die hohen Interessen des Friedens und des Krieges mit den Nationen der anderen drei Teile der Welt zu verhandeln und zu diskutieren. Diese Art von Korporation könnte in einer glücklichen Epoche unserer künftigen Wiederherstellung statthaben [...]. ${ }^{91}$

Nun, diese glücklichen Zeiten sollten - wenn auch nicht in ihrer ganzen erträumten Fülle - nur wenige Jahre später in greifbare Nähe rücken. Was hier noch skeptisch und zögernd, gleichzeitig aber visionär vorgetragen wird, verwandelt sich wenig später in die Leitlinie eines konkreten politischen Handelns: Zwischen dem 22. Juni und dem 15. Juli 1826 fand in der Tat der sogenannte „Congreso de Panamá“ statt. An ihm nahmen Delegierte aus Kolumbien, Peru, Mexiko und Zentralamerika teil, zusammen mit beobachtenden Vertretern aus England und Holland. Die Delegierten aus den USA, den sogenannten, Vereinigten Staaten von Amerika', kamen übrigens zu spät. Argentinien, Chile, Bolivien und Brasilien

90 Vgl. zu diesen Begriffen auch Bitterli, Urs: Die „Wilden“ und die „Zivilisierten“. Die europäischüberseeische Begegnung. München: Deutscher Taschenbuch Verlag 1982.

91 Bolívar, Simón: Escritos políticos, S. 81. 
waren zwar eingeladen worden, verzichteten aber dankend auf eine Teilnahme. Sollte es trotz aller Widerstände doch möglich sein, wirkliche ,Vereinigte Staaten von ganz Amerika' zu schaffen und damit eine panamerikanische Vision in die Tat umzusetzen?

Dieser Traum eines vereinigten Amerika, den Bolívar selbst in der recht aussichtslosen Situation in Jamaica nie zu träumen aufhörte, blieb für sein weiteres politisches Handeln stets ein grundlegender Orientierungspunkt. Wir werden sehen, wie die Idee des Panamerikanismus Bolívars gegen Ende des 19. Jahrhunderts in den USA Eingang finden wird in einen Panamerikanismus-Gedanken, der völlig anderer Natur ist und ein Amerika projiziert, das unter der Vorherrschaft der Vereinigten Staaten stehen sollte. Dieser Panamerikanismus 2.0 hatte freilich nichts mit dem „Panamericanismo“ Simón Bolivvars gemein, sondern war Teil einer hegemonialen Strategie der USA, die bis in unsere Tage erfolgreich bleibt. Inwiefern die wachsende Präsenz Chinas in den Ländern Lateinamerikas heute eine Veränderung dieser Ausgangssituation zu schaffen vermag, werden die kommenden zwei oder drei Jahrzehnte zeigen. Alle Zeichen deuten darauf hin, dass die Vereinigten Staaten von Amerika den Kampf um ihre hegemoniale Stellung in und über Lateinamerika aufgenommen haben.

Gleichwohl wird auch in Lateinamerika, in „Nuestra América“ der Traum der Einheit, verbunden mit dem Aufruf zur Einigung aller Kräfte in Hispanoamerika, auch im letzten Drittel des 19. Jahrhunderts nicht aufgegeben werden. José Martís Essay Nuestra América wird uns eine Konzeption aufzeigen, welche die bolivarianischen Ideen im veränderten weltgeschichtlichen Kontext des ausgehenden 19. Jahrhunderts in neue Zusammenhänge übersetzt und fortzuführen sucht. Bolivars Ideen sind bis heute nicht verwirklicht worden; und vieles spricht dafür, dass es selbst im kleineren Maßstab eines auf Lateinamerika begrenzten „Panamericanismo“ nie zu einer wirklichen politischen Einheit der Länder Lateinamerikas kommen wird.

Dennoch sind die Vorstellungen des Libertador bis heute lebendig geblieben und haben mehrere Generationen lateinamerikanischer Intellektueller in ihren Bann gezogen. Gewiss: Eine Einheit jener, die keine Indianer und keine Spanier, aber auch keine Schwarzen und keine asiatischen Einwanderer sind, konnte nicht für den gesamten Kontinent repräsentativ sein! Bolívar dies aus heutiger Position vorzuwerfen, wäre ebenso anachronistisch und falsch wie der Einwand, die von ihm forcierte Beendigung der Sklaverei habe ausschließlich mit politischem Kalkül zu tun; sie sei nur der Tatsache geschuldet, dass der junge Unabhängigkeitskämpfer, der nach Jamaika später auch in Haiti Aufnahme und Unterstützung beim haitianischen Präsidenten Pétion fand, die Befreiung der Sklaven lediglich auf seine Fahnen geschrieben habe, weil Pétion an diese Zusage seine Unterstützung gebunden habe. 
Manche der Vorstellungen Bolivvars reichen weit über ihre Zeit hinaus; und vielleicht scheiterte der auch politisch und diplomatisch ungeheuer begabte Venezolaner gerade daran und weniger an diktatorischen Formen, die ihm schon die Zeitgenossen häufig mit Recht vorwarfen. Simón Bolívar resignierte an seinem Lebensende, beklagte gar, dass er im Meer gepflügt habe, dass sein Tun also sinnlos gewesen sei und keinerlei Folgen gehabt habe. So heißt es in einem Brief an seinen alten Leutnant, den General Juan José Flores, in einem Schreiben, das Bolívar einen Monat vor seinem Tod verfasste, dass er aus seinem langjährigen Tun nur wenige sichere Ergebnisse habe ziehen können:

Erstens: Amerika ist für uns unregierbar. Zweitens: Wer einer Revolution dient, pflügt im Meer. Drittens: Das einzige, was man in Amerika tun kann, ist emigrieren. Viertens: Dieses Land wird unfehlbar in die Hände der entzündeten Menge fallen, um danach kleineren, kaum wahrnehmbaren Tyrannen aller Farben und Rassen zu gehören. Fünftens: Von allen Verbrechen verschlungen und von der Grausamkeit ausgelöscht, werden die Europäer sich nicht einmal mehr dazu herablassen, uns zu erobern. Sechstens: Wäre es möglich, dass ein Teil der Welt zum ursprünglichen Chaos zurückkehrte, so wäre dies die letzte Periode Amerikas. ${ }^{92}$

Bolívar schrieb dies an einen alten Mitstreiter, der gerade im Begriffe stand, sich in Quito mit seinen Truppen gegen eben jenes Groß-Kolumbien zu erheben, das Bolivar einst erträumt und geschaffen hatte. Gegen Ende seines Lebens war der einst gefeierte Libertador von seinem Amerika enttäuscht und resigniert. Und doch sind seine Ideen auf fruchtbaren Boden gefallen: Als Redner und als Essayist ist er für das gesamte 19. Jahrhundert von grundlegender ideengeschichtlicher und literarischer Bedeutung, eine Tatsache, die nicht zuletzt durch eine Vielzahl von Essays, Ehrungen und Würdigungen im letzten Drittel des Jahrhunderts belegt wird. Noch in den Rhetoriken eines José Martí oder José Enrique Rodó ist Bolívars Redekunst, aber auch seine visionäre Entfaltung panamerikanischer Zielvorstellungen präsent.

Fray Servando Teresa de Mier war in die Kette seiner Verfolgungen (und seiner Verfolger) eingetreten, als er auf die Erscheinung der Jungfrau von Guadalupe zurückgriff und die Evangelisierung Amerikas in eine Zeit vor der Conquista verlegte. Es ist bekannt, welch ungeheuren Einfluss das Symbol dieser Jungfrau im Unabhängigkeitskampf Neuspaniens ausübte. Die Funktionalisierung von Mythen und Legenden für genau umrissene politische Ziele musste daher gerade auch für die Generation der Independencia von großer Wichtigkeit sein,

92 Carta de Bolívar al general Juan José Flores (1830), zitiert nach González Paredes, Ramón: Simón Bolivar, la angustia del sueño. Caracas: Tecnodidacta 1982, S. 662. 
war es doch so möglich, über bestimmte volkskulturelle Elemente die Wirkung politischer Äußerungen und Positionen bei einer breiten Bevölkerung zu vervielfachen.

Zweifellos hat die Funktionalisierung von Mythen für bestimmte politische oder militärische Zwecke eine lange Tradition in Lateinamerika und setzt spätestens mit der Conquista ${ }^{93}$ und - im Staat der Azteken - mit dem Auftauchen von Hernán Cortés ein. Aber auch zu Beginn des 19. Jahrhunderts gibt es zahlreiche Versuche, bestimmte Mythen und Vorstellungen für politische Zwecke einzusetzen und so zu funktionalisieren. Hier machte Simón Bolívar keine Ausnahme, erkannte er doch die Chancen, die sich ihm an dieser Stelle boten.

In seiner Carta de Jamaica etwa diskutiert Simón Bolivar offen die Frage, wie sinnvoll eine politische Funktionalisierung des Quetzalcóatl-Mythos für die Independencia sei. ${ }^{94}$ Dabei wägt er kühl ab, dass „Quetzalcóatl, el Hermes o Buda de la América del Sur“, eher bei Geschichtsschreibern und Literaten als beim einfachen mexikanischen Volk bekannt sei. Die Diskussion um die wahre Bedeutung Quetzalcóatls erscheint ihm daher als zweitrangig, da es ein viel zugkräftigeres und erfolgversprechenderes Symbol kreolischer Einheit gebe:

Glücklicherweise haben die Führer der Unabhängigkeit in Mexiko den Fanatismus höchst zielsicher genutzt, indem sie die berühmte Jungfrau von Guadalupe zur Königin der Patrioten ausriefen; in allen hitzigen Fällen riefen sie sie an und trugen sie auf ihren Fahnen. Dergestalt hat der politische Enthusiasmus eine Mischung mit der Religion erzeugt, was zu einem vehementen Erglühen für die heilige Sache der Freiheit führte. Die Verehrung dieses Bildes in Mexiko ist sogar noch jener überlegen, welche selbst der geschickteste Prophet inspirieren könnte. ${ }^{95}$

Dieses Zitat verdeutlicht eindrucksvoll, wie Bolívar - selbst von keiner eigenen Glaubensbindung an derlei Vorstellungen belastet - bestimmte Mythen und Legenden auf ihre Durchschlagskraft beim gläubigen Volk hin untersucht und deren gezielte Verwendung empfiehlt. Denn durch eine Übertragung aus dem Bereich der Religion auf jenen der Politik kann die Sache der Unabhängigkeit selbst sakralisiert werden. Die Macht über den Mythos ist dabei umso effizienter, je verbreiteter der Glaube an einen bestimmten Mythos beim breiten Volk ist. Die

93 Vgl. hierzu Ette, Ottmar: Funktionen von Mythen und Legenden in Texten des 16. und 17. Jahrhunderts über die Neue Welt. In: Kohut, Karl (Hg.): Der eroberte Kontinent. Historische Realität, Rechtfertigung und literarische Darstellung der Kolonisation Amerikas. Frankfurt am Main: Vervuert Verlag 1991, S. 161-182.

94 Bolívar, Simón: Escritos políticos, S. 82 f.

95 Ebda., S. 83. 
Mythen erfüllen für Bolívar konkrete Funktionen bei der Durchsetzung politischer Ziele, zum Wohle des einfachen Volkes, das über keine Distanz zu Glaubensvorstellungen und Mythen verfügt.

Gleichwohl blitzt an eben dieser Stelle die Gefährlichkeit der Funktionalisierung von Mythen für den Bereich des Politischen und der Politik auf. Simón Bolívar vertritt - vielleicht sogar als erster in Lateinamerika - eine ,moderne‘, aufgeklärte, gleichwohl patriarchalische Form der Funktionalisierung von Mythen und Legenden zu einem politisch-emanzipatorischen Zweck. Es ist aufschlussreich, dass diese Funktionalisierung bei ihm noch auf religiöse Figuren und Muster zurückgreift, während der sich an Bolivar selbst orientierende Mythos dann zu einer säkularisierten Ausdrucksform übergeht, gleichsam zu einer synthetisch geschaffenen Mythenfunktionalisierung: Denn auch der Mythos vom Libertador war und ist politisch höchst einflussreich.

Die Gestalt Simón Bolívars wird zu einem synthetisch geschaffenen Mythos, der eine Vielzahl politischer Leerstellen ebenso besetzen kann, wie dies später bei José Martí der Fall sein sollte, auf den sich alle und jeder im politischen Spektrum Kubas berief. Im Bereich der Mythenfunktionalisierung lässt sich zweifellos im Übergang von der Independencia zu den politisch unabhängigen Republiken eine deutliche Säkularisierung feststellen. Wie Simón Bolívar und Fray Servando Teresa de Mier beispielhaft zeigen, haben sich die Bewohner der ehemals spanischen Kolonien nun, an der Schwelle zum 19. Jahrhundert, des Glaubens beziehungsweise der Mythen amerikanischen wie europäischen Ursprungs bemächtigt und setzen sie für ihre Zwecke und Ziele sehr bewusst ein. Eine solche Haltung ist zwar auf der einen Seite noch deutlich einem aufklärerischen Bewusstsein und einer kühlen Rationalität verpflichtet, intendiert aber andererseits eine fundamentale Emotionalisierung von Politik, wie sie das weitere 19. Jahrhundert und nicht nur dieses! - charakterisieren sollte.

Der Ausklang von Bolívars berühmtem Brief soll den Schlusspunkt unserer recht ausführlichen Beschäftigung mit dem Libertador setzen. Er situiert sich in gewisser Weise zwischen den Vorstellungen Humboldts von der Zukunft Amerikas und Hegels Rede von Amerika als Kontinent der Zukunft, öffnet sich folglich unverkennbar auf die Herausforderungen des 19. Jahrhunderts. Ich möchte Ihnen diese Passage ganz am Ende des Briefes daher nicht vorenthalten, wirft sie doch ein bezeichnendes Licht auf das Sendungsbewusstsein und die Zukunftshoffnung der amerikanischen Kreolen:

Sind wir erst einmal unter den Auspizien einer liberalen Nation stark, welche uns ihren Schutz gewährt, wird man uns einvernehmlich die Tugenden und die Talente kultivieren sehen, die zum Ruhme führen; dann werden wir den majestätischen Marsch zu jenem großen Wohlstande und Wohlbefinden antreten, zu denen das südliche Amerika bestimmt 
ist; dann werden die Wissenschaften und die Künste, welche im Orient entstanden und Europa erleuchteten, dem freien Kolumbien, das ihnen Asyl gewähren wird, zufliegen. ${ }^{96}$

Das künftig freie Amerika, das Bolívar vorzugsweise geographisch als „América del Sur“ oder „América meridional“ bezeichnet, um der Verwendung des Begriffs „América española“ zu entkommen, wird damit eingebaut in einen welthistorischen Kulturprozess. Dieser nimmt vom Morgenland seinen Ausgang, erreicht in Europa einen ersten Höhepunkt und folgt weiterhin einer Westwanderung, die wir als eine doppelte Translatio bezeichnen dürfen: als „Translatio imperii“ und „Translatio studii“. Die Überzeugung von der Wanderung des Meridians von Macht und Wissen nach Westen wird im Übrigen in den Vereinigten Staaten von Amerika zum gleichen Zeitpunkt zu der Vorstellung führen, dass die Westwanderung der Weltmacht bald schon von Europa über den Atlantik nach Amerika überspringen werde.

Wichtig für unsere Überlegungen und den weiteren Fortgang unserer Vorlesung freilich ist, dass diese majestätische Zukunftsvision das indianische oder schwarze Element in starkem Maße ausblendet und marginalisiert. Bolívars Amerika ist auf kulturellem Gebiet - wie wir hier überdeutlich sehen - keineswegs ein „mundo aparte“. Es ist vielmehr eindeutig rückgebunden an die Alte Welt: Bolívars Amerika ist noch immer über eine kulturelle Nabelschnur mit Europa verbunden und an Europa gebunden, auch wenn es politisch seine Unabhängigkeit erfolgreich zu erreichen trachtet.

96 Bolívar, Simón: Escritos políticos, S. 84. 